\title{
How does monitoring set the stage for adaptive regulation or maladaptive behavior in collaborative learning?
}

\author{
Márta Sobocinski $^{1} \cdot$ Sanna Järvelä ${ }^{1} \cdot$ Jonna Malmberg ${ }^{1} \cdot$ Muhterem Dindar $^{1}$ • \\ Antti Isosalo $^{2} \cdot$ Kai Noponen ${ }^{2}$
}

Received: 11 June 2019 / Accepted: 16 April 2020/Published online: 6 May 2020

(C) The Author(s) 2020

\begin{abstract}
In collaborative learning situations, monitoring is needed to maintain common progress toward shared goals. The present study aimed to analyze group-level monitoring events, as well as groups' reactions to these events, to identify instances of adaptive regulation and maladaptive behavior. Three dimensions of monitoring events were qualitatively coded from video data: the monitoring target, valence, and phase, which provided insight into identifying critical moments during the collaborative process when regulation is needed. By looking at what kind of monitoring the groups engaged in, and how the groups progressed after the need for regulation arose, different types of adaptive regulation and maladaptive behavior were distinguished. In addition, group-level physiological state transitions in the heart rate were explored to see whether changes in regulation (adaptive regulation and maladaptive behavior) were reflected in the state transitions. Nine groups of three students each participated in a collaborative exam for an advanced high school physics course, during which video and heart rate data were collected. The results showed that on-track sequences were the most common, followed by adaptive sequences. The temporality of these sequences was examined, and four categories of group progress are described with case examples. A correlation analysis showed that physiological state transitions were positively correlated with on-track sequences. The opportunities and limitations of using three dimensions of monitoring and heart-rate based physiological state transitions to study adaptive regulation are discussed.
\end{abstract}

Keywords Collaborative learning $\cdot$ Monitoring $\cdot$ Adaptation $\cdot$ Socially shared regulation of learning $\cdot$ Heart rate

Márta Sobocinski

marta.sobocinski@oulu.fi

Extended author information available on the last page of the article 


\section{Introduction}

It is known that collaborative learning is not a straightforward process. Various challenges arise during collaboration (Kreijns et al. 2013), and group members must recognize these situated challenges as they arise during the learning process (Koivuniemi et al. 2018). To solve recognized challenges (cognitive, motivational, emotional, and social) together, group members are required to regulate their learning (Hadwin et al. 2018b). However, researchers have shown that groups need support in effectively regulating their learning (Järvelä and Hadwin 2013). Technological tools aimed at supporting students' awareness of emotional, motivational, and cognitive challenges have been developed (Azevedo and Witherspoon 2009; Järvelä et al. 2015; Järvenoja and Järvelä 2009; Malmberg et al. 2010), which might affect the strategies groups use later during collaboration (Kreijns et al. 2003). Recently, interest in producing adaptive support for collaborative learning has increased: However, for face-to-face scenarios, this support requires a better understanding of the regulatory processes underlying collaboration, to deliver the support when it is needed (Noroozi et al. 2018; Rummel et al. 2016). This study builds on the socially shared regulation of learning (SSRL) framework, which can provide essential guidelines for detecting and responding to challenges in a collaborative learning situation.

SSRL has been identified as an important prerequisite for successful collaborative learning (Khosa and Volet 2014). This process involves setting a joint goal, monitoring progress toward that goal and regulating the learning process by making adjustments to cognitive, emotional, motivational and behavioral states as needed (Hadwin et al. 2018b). When individuals face a challenge, they recognize the need for regulation through monitoring, which in optimal situations, is followed by strategic and adaptive regulation (Hadwin et al. 2018a). Winne (2010) described the regulated learning process in terms of an IF-THEN contingency: If monitoring reveals a problem, then metacognitive control is triggered. However, students often do not recognize a need for regulation, or they fail to regulate their learning (Winne et al. 2017), which is a sign of maladaptive behavior. If monitoring shows that the group is progressing toward their goal (i.e., they are on track), then there is no need to regulate their learning. Recognizing challenges and verbalizing the need for regulation through shared monitoring sets the stage for shared regulation to occur.

SSRL (Hadwin et al. 2018b) describes the process of regulation as a cyclical loop consisting of weakly sequenced phases, which are recursive; that is, the products of one phase inform the standards of the next. However, studies that empirically identified a need for regulation and the following instances of adaptive regulation and maladaptive behavior in a learning process are scarce (Bakhtiar et al. 2017; Binbasaran Tuysuzoglu and Greene 2014; Pieschl et al. 2012). For educators to offer timely support, it is necessary to recognize these critical moments when they occur, and it is necessary to understand when students engage in adaptive regulation or maladaptive behavior following the monitoring instances that occur during critical moments. The problem, however, is that regulatory processes during learning are not easy to capture, as they are internal, metacognitive processes. Due to technological developments, the field has recently advanced in using physiological measures to detect group-level regulatory processes (Haataja et al. 2018; Järvelä et al. 2019; Malmberg et al. 2018; Pijeira-Díaz et al. 2019).

The present study investigated how sequences of different monitoring events and groups' reactions to the sequences can indicate adaptive regulation or maladaptive behavior, and how 
these sequences are related to group-level physiological states discovered by vector quantization of heart rate data (Gersho and Gray 1991). The contribution of the study is that first, it empirically identified instances of groups' need for regulation and second, provided an empirical framework based on the theory for how to identify adaptive regulation or maladaptive behavior from the process data. Third, the study investigated the relation between shifts in group metacognitive activity marked by monitoring and transitions in group-level physiological states.

\section{Theoretical framework}

The self-regulated learning (SRL) framework proposes that successful learners monitor and regulate learning content and the processes they apply to the content when pursuing their learning goals and enhancing their knowledge (Winne 2019). Simply put, self-regulating students deliberately look for the most appropriate means to learn better and achieve more (Winne 2010). Winne and Hadwin's (1998) model of SRL explains how learners cyclically and recursively adapt their regulation through four loosely sequenced phases (Winne and Hadwin 1998). In Phase 1 (task understanding) learners create a cognitive, motivational, and emotional profile of the learning task and its surrounding environment. In Phase 2 (goals and planning), learners decide on the goals and make plans about how to achieve them. In Phase 3 (task enactment), learners apply tactics and strategies to reach their goals and update their strategies as the learning unfolds. In Phase 4 (reflection and adaptation), learners reflect on the features of the previous phases and consider updating products from the previous phases or their underlying beliefs.

In each phase of regulated learning, there is an interplay between cognitive, motivational and affective processes. In the MASRL model, Efklides (2011) describes in details how different layers of metacognition (i.e. metacognitive experiences, metacognitive knowledge), cognition and affect interact as the learner executes the task at the person level and at the person - task level. However, learning does not happen in isolation, but rather through social interaction and either one of previously mentioned models do not take account the social context. When learning in groups, regulation happens both on an individual (SRL) and on a group level (socially-shared regulation of learning, SSRL). In this study, regulation of learning is viewed from theoretical framework of SSRL (Hadwin et al. 2018b) which is built on Winne and Hadwin's 1998 SRL model. An increasing number of empirical studies have shown that groups that engage in SSRL often outperform those that do not (Järvelä et al. 2013; Zheng et al. 2019). When engaging in either in SSRL, learners negotiate a common perception of the task, set shared goals and standards, and choose strategies that support the attainment of the shared goals (Hadwin et al. 2018b). During such processes, learners need to continuously be aware whether the group is progressing using their metacognition. Metacognition is comprised of two main processes: monitoring and control (Nelson and Narens 1994). Metacognitive monitoring is a central process in both SRL and SSRL (Hadwin et al. 2018b). This is because monitoring evaluates the ongoing learning performance and informs learners about the necessary actions to be taken in order to reach a specific performance outcome or criteria (de Bruin and van Gog 2012). Such information provided by monitoring facilitates the metacognitive control processes that guide the self- and shared regulatory processes during learning. In this regard, it can be concluded that monitoring fuels SRL and SSRL in collaborative learning. 


\section{Importance of monitoring in regulated learning}

Models of self- and socially shared regulation of learning consider metacognitive monitoring and control as critical processes that predict learning outcomes (Hadwin et al. 2018a; Winne and Hadwin 1998; Zimmerman 2013). Previous empirical research examined monitoring and strategy use separately. However, recently interest in exploring how these processes interact with each other during the learning process has been growing (Ben-Eliyahu and Bernacki 2015; Binbasaran Tuysuzoglu and Greene 2014; Deekens et al. 2018).

Previous research on monitoring focused, for example, on monitoring accuracy (Thiede et al. 2009), although educational researchers considered monitoring in a broader sense, including different types of monitoring, in their studies, such as monitoring of goals (Harkin et al. 2016), strategy use (Deekens et al. 2018), and motivation and emotions (Griffin et al. 2013; Wolters 2003). That is, monitoring has a broad focus, especially in the context of SRL and SSRL.

Monitoring is central for regulation. For example, Deekens et al. (2018) found that students who enacted deeper strategies also monitored their learning more frequently, resulting in better performance. Binbasaran Tuysuzoglu and Greene (2014) studied the relationship between metacognitive monitoring and control in a hypermedia learning environment. They differentiated between adaptive use of strategy (change in the use of strategies) and static use of strategy, after verbalized monitoring. The authors found that learners' adaptive use of strategy is positively related to learning, and concluded that learners rely on monitoring to regulate subsequent learning activities. Zhou (2013) used traces from an online learning environment to analyze patterns of self-regulatory activities, and found that mastery-approach-dominant students revisit the task instructions after a series of actions related to task enactment (searching, selecting, and accessing information).

Although monitoring is a mental process, collaborative learning situations require learners not only verbalize their own mental monitoring process but also control the learning processes through interaction. For example, Fransen et al. (2011) argued that communicating and coordinating group actions play a crucial role during the collaborative process. This communication is important for SSRL, if there is a need, for example, to negotiate the use of the strategies to ensure progress toward shared goals. The transactivity of the discourse, that is, reacting to and building on each other's ideas, has been linked with a positive influence on the outcomes of the collaboration (Noroozi et al. 2013). Previous research showed that social interaction is necessary to successfully overcome challenges (Kreijns et al. 2013), and ignoring challenges can affect the general work atmosphere, and cause unequal participation (Koivuniemi et al. 2018).

\section{Valence of monitoring, adaptive regulation, and maladaptive behavior}

According to the SSRL framework, monitoring can occur during all phases of learning (task definition, goals and planning, task enactment, or reflection), and can be directed at cognition, motivation, emotion or behavior, (Hadwin et al. 2018a). When monitoring reveals a mismatch between the standards set and the current product, it signals a need for regulation of learning (Winne and Hadwin 1998). However, not all monitoring events reveal a mismatch; sometimes, monitoring shows that the group is progressing toward their goal. For this reason, Azevedo (2009) suggested considering the valence of monitoring statements (positive: we are making progress, vs. negative: this is not correct), to be able to gain insight into the feedback loops 
between monitoring and control. The valence of monitoring can reveal whether the group is "on track" or faces challenges. Specifically, monitoring events with negative valence can be considered critical moments for the development of adaptive or maladaptive strategy use (Azevedo et al. 2010). Negative valence can signal either that the group is off-track or that the group is facing a challenge, which requires further action.

After monitoring events with negative valence (i.e., a revealed need for regulation), learners can use the information gained to strategically control their learning (Winne and Hadwin 1998), either through making adjustments to enacted strategies or by strategically adapting their task perceptions and plans. However, in some cases, learners fail to do so, and engage in maladaptive behavior instead (Järvelä and Hadwin 2013). Examples of maladaptive behavior include failing to interact productively in groups (Barron 2003; Janssen et al. 2010), using static strategies after negative judgments of learning (Binbasaran Tuysuzoglu and Greene 2014), not establishing shared goals and standards (Kwon et al. 2014), and ignoring experienced challenges (Koivuniemi et al. 2018).

Previous researchers explored the adaptivity of learning processes through off-line measures, such as self-reports (Martin 2007) or surveys used to measure goals and goal structures (Anderman and Midgley 2002). Recent studies used process-oriented methods, aiming to capture adaptive regulation as it happens. For example, Malmberg et al. (2013) investigated how high- and low-achieving students' cognitive learning patterns differ in challenging learning situations. The results showed that the typical cognitive learning pattern of lowachieving students ended with labeling information "I don't know," whereas high-achieving students' learning patterns revealed the use of deep cognitive strategies. In this case, the lowachieving students exhibited maladaptive behavior, whereas the high-achieving students showed strategic adaptations, despite the challenges. Kwon et al. (2014) explored social interactions of six collaborating groups during an undergraduate online course. They analyzed group regulation patterns, and considered it adaptive group regulatory behavior when groups strategically coordinated their work, scheduled in advance and engaged in group level monitoring.

Su et al. (2018) investigated language learners' regulatory behaviors in a computer supported collaborative learning context. Participants completed wiki-supported collaborative reading activities in the context of learning English as a foreign language over a semester. Sequential analysis of the students' chat logs revealed that high-performing groups showed a pattern of content monitoring, organizing, and process monitoring, which the authors considered a sign of adapting group regulation processes. Low-performing groups showed a pattern of organizing after organizing, a sign of limited regulatory skills.

Besides process-oriented methods, there are also novel data sources that can be used to study regulation in collaborative learning: in a special issue focusing on promoting and researching adaptive regulation in computer-supported collaborative learning, Winne (2015) summarized the direction of the field, and pointed to the importance of using novel methods and data sources to trace and identify shifts in metacognitive activity, as collaboration evolves over time.

\section{Multimodal data channels for detecting and measuring regulatory processes}

In recent years, interest in using multimodal data, such as psychophysiological measures combined with video data, to investigate learning processes in collaborative learning has increased (Ahonen et al. 2018; Haataja et al. 2018; Pijeira-Díaz et al. 2019). This increase is 
due to the complex, cyclical, and partly invisible nature of regulation processes. Azevedo (2015) pointed out that if we want to understand cognitive, motivational or emotional, and behavioral changes in regulation as they occur, there is no single data channel that can reliably capture them all.

Previous research has used various data combinations in an attempt to capture aspects of regulated learning, such as log data and facial recognition data (Taub et al. 2019), eye tracking and log data (e.g. Mudrick et al. 2018), self-reports and physiological data (Pijeira-Díaz et al. 2018). The present study is based on our previous work investigating the temporality of SSRL processes detected from video data and their relationship to physiological indexes (Haataja et al. 2018; Järvelä et al. 2019; Malmberg et al. 2018; Pijeira-Díaz et al. 2019).

When studying group processes, previous empirical studies investigated the relationship between physiological arousal and the level of interaction (Malmberg et al. 2018), physiological synchrony and monitoring (Dindar et al. 2019; Haataja et al. 2018), and physiological synchrony and small-scale adaptation (Sobocinski et al. 2019). Haataja et al. (2018) found a connection between the monitoring frequency and the physiological synchrony of high school students solving a task related to nutrition, and concluded that physiological synchrony has the potential to reveal shared regulation processes. Physiological synchrony is an established method for looking at group level physiological signals (e.g. Elkins et al. 2009; Haataja et al. 2018; Montague et al. 2014; Pijeira-Díaz et al. 2016; Strang et al. 2014), however, it only provides information about when group members are in synchrony, while leaving a significant portion of the data (where there is no synchrony) unaccounted for. In order to overcome this limitation, Pijeira-Diaz et al. (2019) looked at when learners were in high arousal state during collaboration, and how the high arousal state "spread" across the group. He found that students were in a high-arousal state at the same time just $4 \%$ of the time they collaborated.

However, the above mentioned studies did not examine how monitoring sequences can used as an indicator of adaptive regulation, and how this regulation is related to shifts in grouplevel physiological states. Viewing a collaborative group as a dynamic system opens up an array of analytical methods that can potentially extend our understanding of how different regulatory processes are connected with each other and with the physiological data gathered from the group (Hilpert and Marchand 2018). Focusing on the temporality of shifts in metacognitive activity combined with transitions in group-level physiology can provide a gateway to study adaptation in SSRL as it unfolds. The aim of this study was to find a method that allows us to detect subtle, but significant, changes in the heart rate values of the three students. Treating the collaborating group as a dynamic system, it was possible to compress the information from the three heart rate data streams, and examine what states the system underwent, and how much time each group spent in each state.

\section{Aim}

The aim of the study was to investigate monitoring events, in order to identify instances of adaptive regulation and maladaptive behavior. In addition, group-level physiological state transitions in the heart rate were explored to see whether changes in regulation (adaptive regulation and maladaptive behavior) were reflected in the state transitions. The following questions guided the research: (RQ1) What kind of monitoring, in terms of target, valence, and phase appears during the collaboration, and to what extent do groups react to the different types of monitoring? (RQ2.1) How do maladaptive, adaptive, and on-track sequences occur 
during collaboration? (RQ2.2) What is the relation between adaptive and maladaptive sequences in groups' physiological state transitions?

\section{Method}

\section{Participants}

The participants $(N=31$, age 16-17 years, 8 female and 23 male) were high school students enrolled in an advanced high school physics course in a school in Northern Finland. The course was not compulsory, and it required students to have completed two other physics courses. All participants were informed about the details of the data collection, and were told that participation would not affect their grade in any way, and that they could revoke their consent at any time during the data collection. All students gave their written consent to participate in the study.

Throughout the course, students worked collaboratively in groups of three (one group of four). The students remained in the same groups throughout the course. The collaborating groups were formulated based on heterogeneity of learning regulation profiles for the sake of between-team comparability. Students were asked to fill out the cognitive and metacognitive strategies section of the Motivated Strategies for Learning Questionnaire (MSLQ) questionnaire (Pintrich et al. 1991) as a measure of their learning profile. Based on the students' questionnaire score, they were categorized into three self-regulation groups: low $(M=114.5$, $\mathrm{SD}=12.3)$, middle $(\mathrm{M}=140.7, \mathrm{SD}=5.5)$, and high $(\mathrm{M}=161.8, \mathrm{SD}=11.2)$. Each group included one student from each category.

At the end of the course, students had to take an exam that had two parts: an individual part and a collaborative part. This study focused on the collaborative exam. The exam was a higher stake situation than the lessons, and it was assumed that more instances of monitoring would occur during the collaborative exam situation. This is because students had to deliver a group product with the best possible quality, and within a specific duration in order to succeed in the course. Thus, a high interdependency and collaboration among the group members was expected during the exam. The task was to determine the refractive index of light for water using the standard equipment provided for each lesson that included necessary and unnecessary items (laser, a container for the water, an angle measure, and various prisms and lenses). Students were allowed to use a reference book that contained formulas and standard values, including the refractive index of light for water. The requirement was to prepare a report of their experiment that included a drawing and a description of the setup, the formula used and calculations made, the final result, and an evaluation of this result. The teacher assessed these reports, and all groups received scores between 5.0 and 5.5 out of a possible 6.0.

\section{Data collection}

Video data were collected from the collaborative exam, which lasted for an hour. The students were allowed to leave early. The exam consisted of students arriving, taking out their iPads, getting into groups, and doing the collaborative task. For the purpose of this study, only the actual collaboration was analyzed. After a quality check, one group's data had to be discarded because of faulty audio. From the nine remaining groups, a total of $5 \mathrm{~h} 14 \mathrm{~min} 46 \mathrm{~s}$ of video data was analyzed $(M=34 \min 58 \mathrm{~s}, S D=16 \min 7 \mathrm{~s})$. 
For collecting physiological data, Empatica S4 bracelets were used on nine students (three randomly chosen groups). This was due to the fact that there were not enough bracelets for all the students. The other students were fitted with similar-looking "dummy" bracelets to avoid students feeling singled out. Students were fitted the bracelets at the beginning of the session, and were informed that they could be taken off if they were uncomfortable. In this study, we used the heart rate measurements collected by the Empatica bracelets from the three groups equipped with them.

\section{Video data analysis}

The video data analysis was completed in two stages. In stage one, monitoring instances were identified based on utterances. The mean duration of monitoring was $13 \mathrm{~s}(\mathrm{SD}=21 \mathrm{~s})$. Three dimensions of monitoring were coded from the identified monitoring instances: target (cognition, motivation, emotion, behavior), valence (positive or negative), and phase in which monitoring occurs (task definition, goals and planning, task enactment, or reflection). Next, the reaction (or lack of) that immediately followed the monitoring instances was marked. Fig. 1 presents a diagram of the coding categories related to monitoring from stage one. It should be noted that no off-task behavior was found in the data as the task was in an exam situation with a time limit.

As the video data used in this study were a subset of a larger study, reliability coding was performed, taking into account the whole data set. Twenty percent of the identified monitoring episodes were randomly chosen to be coded by the second coder, who was given the coding manual. For the target of monitoring, a good agreement was achieved (McHugh 2012), Cohen's $k=.74$. For the valence of monitoring, the agreement was moderate (Cohen's $k=$ 0.69 ), as well as for phase of monitoring (Cohen's $k=0.68$ ). The reaction after these monitoring episodes was also coded by the second coder, resulting in Cohen's $k=0.67$. The discrepancies were discussed and the definitions of coding categories were negotiated until consensus was reached, and the data was recoded to reflect the complete agreement.

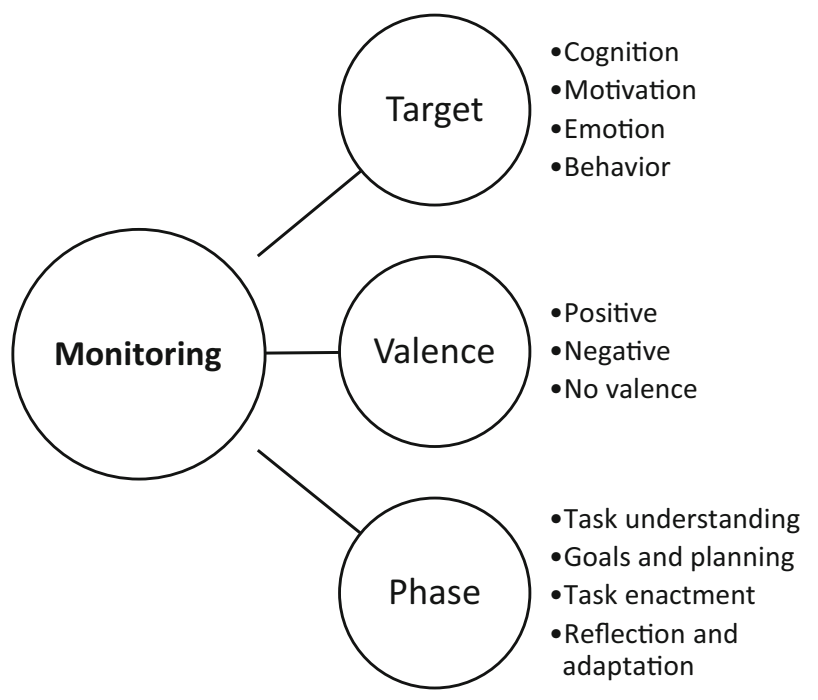

Fig. 1 Diagram of the coding categories of monitoring events 
First, monitoring instance was identified, the monitoring target was coded based on the criteria presented in Table 1. In the next stages of analysis, monitoring emotion and monitoring motivation were combined into one category because of their low frequency.

Second, because regulation is a cyclical feedback loop, the regulated learning phase in which monitoring occurred (task definition, goals and planning, task enactment, or reflection), was coded, based on Winne and Hadwin's (1998) model, using Winne's (2011) detailed descriptions of the phases. The main criteria and examples are presented in Table 2.

Third, valence was identified. The concept of valence of monitoring is based on Azevedo (2009). Valence was coded for monitoring cognition and motivation or emotion; monitoring behavior was considered not to have valence. For monitoring cognition, negative valence was assigned for negative judgments of learning, as well as monitoring cognition that revealed uncertainty ("I don't know how we could do this"), feeling of difficulty ("If we are really supposed to do it like this, it's going to be really hard"), or that the outcome or progress did not match the goals ("Our value is way off"). Monitoring cognition with positive valence was identified when students recognized progress, or assessed the outcome as correct ("That value is close enough!"). For monitoring motivation or emotion, negative valence was assigned if the statement expressed negative feelings ("This blows!") or motivational states ("I just can't anymore..."), as opposed to positive feelings ("I'm psyched!”) or positive attitudes ("I think our group will do great!").

Table 1 Description of Coding Categories for the Targets of the Monitoring Episodes

\begin{tabular}{|c|c|c|}
\hline Code & Description & Examples \\
\hline Monitoring cognition & $\begin{array}{l}\text { Monitoring task understanding, } \\
\text { previous } \\
\text { knowledge, task product, content } \\
\text { understanding, or procedural } \\
\text { knowledge }\end{array}$ & $\begin{array}{l}\text { I'm not sure how we are supposed } \\
\text { to do this. } \\
\text { We at least know from previous } \\
\text { lessons that the speed of light } \\
\text { won't change. } \\
\text { I have no idea what I'm now doing. } \\
\text { How we are supposed to use the } \\
\text { formula here? } \\
\text { Is this result in a reasonable range? } \\
\text { Are we still adding something, or } \\
\text { do you think this is ready? } \\
\text { I'm not sure what critical angle } \\
\text { means? } \\
\text { This should work according to } \\
\text { the same principle as earlier. }\end{array}$ \\
\hline $\begin{array}{l}\text { Monitoring } \\
\text { motivation }\end{array}$ & $\begin{array}{l}\text { Student monitors the current trend in } \\
\text { motivation, includes monitoring } \\
\text { volition and self-efficacy }\end{array}$ & $\begin{array}{l}\text { Who is willing to draw this? } \\
\text { Our motivation is on a good track. } \\
\text { I really would not want to do this. } \\
\text { I'm so bad at drawing. Who can do this? }\end{array}$ \\
\hline Monitoring emotion & Monitoring emotional state & $\begin{array}{l}\text { My feelings are good! Let's start! } \\
\text { These microphones make me annoyed... } \\
\text { This is exciting! }\end{array}$ \\
\hline Monitoring behavior & $\begin{array}{l}\text { Monitoring task-related behavior, } \\
\text { resources needed for the task and } \\
\text { task progression }\end{array}$ & $\begin{array}{l}\text { Have you all now read the whole paragraph? } \\
\text { I wonder if this is a good place for this laser } \\
\text { Is someone writing up our results? } \\
\text { Do we have all the equipment needed? } \\
\text { How much time do we have left? } \\
\text { We still have three tasks to do. }\end{array}$ \\
\hline
\end{tabular}


Table 2 Description of Coding Categories for the Phases of the Monitoring Episodes

\begin{tabular}{lll}
\hline Code & Description & Examples \\
\hline Task definition & Forming or redefining & So did we have to do this too? \\
& task understanding & Are we supposed to write this on paper? \\
& & Do we just have to find the value? \\
Goal setting and & Defining an acceptable level of & Let's just use trial and error until we get the \\
planning & achievement & correct value. \\
& Making concrete plans & Our aim is to ace this. \\
Task enactment & Evaluating the progress against the & How should we proceed with this? \\
& standards set & Should we check if this is correct? \\
Reflection and & while working on the task & This isn't working. \\
adaptation & Strategies and ways of working & Well, we didn't manage to finish everything. \\
\hline
\end{tabular}

Next, after each monitoring event, the group reaction was coded. If the group acknowledged the monitoring by further discussing it, or by responding to it (such as "aha", "hmm...", "yes"), the response was coded as a reaction. If the group continued the discussion while ignoring the monitoring, the behavior was considered a lack of reaction.

In the second stage of video coding, on-track, adaptive and maladaptive sequences were identified based on the type of monitoring that occurred (target, valence, phase), and the group's reaction or lack of reaction to it. In the following, the criteria for identifying these sequences are presented, along with examples illustrating how each type of sequence was coded based on the monitoring and reaction codes.

\section{On-track sequences}

The monitoring events with positive valence revealed no need for regulation in this study, so they were considered to signal that the group was on track. The monitoring behavior events were not coded for valence, and were considered a sign that the group was on track, because it was seen that they were enabling the coordinated functioning of the group. Table 3 shows two examples of on-track sequences from the same group, from near the end of the work process.

\section{Adaptive sequences}

Sequences where monitoring events with negative valence were followed by a group reaction were considered adaptive sequences. In Table 4, an example of data is presented, showing how the adaptive sequence was coded based on monitoring events with negative valence and reaction codes. In the example, the group is close to finishing a task, but they were concerned about the accuracy of their results. All group members participated in the discussion, continuously monitoring their cognition. Throughout the episode, they remained in the task enactment phase.

\section{Maladaptive sequences}

When monitoring events with negative valence were not followed by a group reaction, they were considered maladaptive. Table 5 presents an example of a maladaptive sequence, 
Table 3 Example of On-track Sequences Coded in the Data

\begin{tabular}{|c|c|c|c|c|c|}
\hline Sequence & $\begin{array}{l}\text { Monitoring or } \\
\text { Reaction }\end{array}$ & $\begin{array}{l}\text { Monitoring } \\
\text { target }\end{array}$ & $\begin{array}{l}\text { Monitoring } \\
\text { phase }\end{array}$ & $\begin{array}{l}\text { Monitoring } \\
\text { valence }\end{array}$ & Group 5, 38:49-39:10 \\
\hline On-track & Monitoring & Cognition & Task enactment & Positive valence & $\begin{array}{l}\text { Student 1: So we have the } \\
\text { calculations, the steps, } \\
\text { and the arguments }\end{array}$ \\
\hline On-track & $\begin{array}{l}\text { Monitoring } \\
\text { Reaction }\end{array}$ & Behavior & Task enactment & - & $\begin{array}{l}\text { Student 3: Should we have a } \\
\text { drawing as well? } \\
\text { Student 2: Yes! (starts drawing) }\end{array}$ \\
\hline
\end{tabular}

followed by an on-track sequence to illustrate how the group continued the collaboration while ignoring a monitoring event with negative valence. In this situation, the group was close to finishing the task. One student felt that their answer was not deep enough; however, the other two students were eager to wrap it up. The group handed in the task $2 \mathrm{~min}$ after this interaction occurred.

\section{Heart rate data analysis}

We also investigated how adaptation, a process aimed at changing group behavior, is reflected in the groups' physiological state transitions based on heart rate (HR) measurements collected from each group member. Because the focus was on group-level processes, we considered the

Table 4 Example of Adaptive Sequences Coded in the Data, Followed By an On-Track Sequence

\begin{tabular}{|c|c|c|c|c|c|}
\hline Sequence & $\begin{array}{l}\text { Monitoring } \\
\text { or Reaction }\end{array}$ & $\begin{array}{l}\text { Monitoring } \\
\text { target }\end{array}$ & $\begin{array}{l}\text { Monitoring } \\
\text { phase }\end{array}$ & $\begin{array}{l}\text { Monitoring } \\
\text { valence }\end{array}$ & Group 3, 22:53-23:27 \\
\hline \multirow[t]{5}{*}{ Adaptive } & Monitoring & Cognition & $\begin{array}{l}\text { Task } \\
\text { enactment }\end{array}$ & $\begin{array}{l}\text { Negative } \\
\text { valence }\end{array}$ & $\begin{array}{l}\text { Student 1: Should we evaluate the } \\
\text { correctness of the result? Like } \\
\text { what could cause the measurement } \\
\text { error? }\end{array}$ \\
\hline & Reaction & & & & $\begin{array}{l}\text { Student 2: Yes, we could explain } \\
\text { more there... }\end{array}$ \\
\hline & & & & & $\begin{array}{l}\text { Student } 3 \text { (at the same time): Put } \\
\text { there that we saw... }\end{array}$ \\
\hline & & & & & $\begin{array}{l}\text { Student 2: Yes, that when we } \\
\text { pointed the laser in that } \\
\text { direction }\end{array}$ \\
\hline & & & & & Student 3: hmmm \\
\hline \multirow[t]{5}{*}{ Adaptive } & Monitoring & Cognition & $\begin{array}{l}\text { Task } \\
\text { enactment }\end{array}$ & $\begin{array}{l}\text { Negative } \\
\text { valence }\end{array}$ & $\begin{array}{l}\text { Student 1: Ok, so I'll write that... } \\
\text { did we calculate the refraction } \\
\text { rate of the water? }\end{array}$ \\
\hline & Reaction & & & & Student 2: Yes \\
\hline & & & & & $\begin{array}{l}\text { Student } 1 \text { : So, (writing...) The } \\
\text { result was... }\end{array}$ \\
\hline & & & & & Student 2: .329 \\
\hline & & & & & Student 1: aha \\
\hline \multirow[t]{2}{*}{ On-track } & Monitoring & Cognition & $\begin{array}{l}\text { Task } \\
\text { enactment }\end{array}$ & $\begin{array}{l}\text { Positive } \\
\text { valence }\end{array}$ & $\begin{array}{l}\text { Student 3: That's actually a quite } \\
\text { accurate number, if we got } .329\end{array}$ \\
\hline & Reaction & & & & $\begin{array}{l}\text { Student } 1 \text { : That's true... (Erasing)... } \\
\text { so maybe I just write that the } \\
\text { result was close to what we } \\
\text { expected }\end{array}$ \\
\hline
\end{tabular}


Table 5 Example of a Maladaptive Sequence Coded in the Data, Followed By An On-Track Sequence

\begin{tabular}{llllll}
\hline Sequence & $\begin{array}{l}\text { Monitoring } \\
\text { or Reaction }\end{array}$ & $\begin{array}{l}\text { Monitoring } \\
\text { target }\end{array}$ & $\begin{array}{l}\text { Monitoring } \\
\text { phase }\end{array}$ & $\begin{array}{l}\text { Monitoring } \\
\text { valence }\end{array}$ & Group 1, 24:39-24:46 \\
\hline Maladaptive & $\begin{array}{l}\text { Monitoring } \\
\text { No reaction }\end{array}$ & Cognition & $\begin{array}{c}\text { Task } \\
\text { enactment }\end{array}$ & $\begin{array}{c}\text { Negative } \\
\text { valence }\end{array}$ & $\begin{array}{c}\text { Student 1: We might need } \\
\text { to write more arguments, } \\
\text { no? }\end{array}$ \\
& Monitoring & Behavior & $\begin{array}{c}\text { Task } \\
\text { enactment }\end{array}$ & - & $\begin{array}{c}\text { Student 2: Did we write our } \\
\text { names on the paper? } \\
\text { Student 3: Not yet (starts } \\
\text { writing the names...) }\end{array}$ \\
\hline
\end{tabular}

group as a dynamical system characterized by the aggregated HR state of all the group members. We focused on identifying essential group HR dynamics describing significant changes in groups' aggregated HR state (physiological state transitions).

In this study, the previously described task was approached using vector quantization (VQ) (Gersho and Gray 1991). This technique allowed the reduction of the number of system states and transitions between them, giving rise to delineable recurrent state patterns. Traditionally, VQ has been used in information compression, for example, in audio signal processing (Gray 1984). In recent years, with the emerge of big data, vector quantization has been used, for example, in analyzing timeline-based location information (Xu et al. 2019), or to group movie frames with a visual vocabulary (Sivic and Zisserman 2003).

To represent the aggregated physiological state of the group, we collected each participant's HR into an ordered triplet; a three-dimensional vector having the HRs as its elements. As the HR values varied continuously over time, the HR triplets traced out a three-dimensional trajectory describing the state at each time instant. For each group, a state trajectory was produced from the beginning to the end of the collaborative exam, as presented in fig. 2.

In order to identify significant changes in the continuously varying state, the HR triplet values were discretized using VQ coalescing similar triplet values into a discrete state and encoding major changes in the triplet values as transitions between those states. In other words,

\section{Group 1}

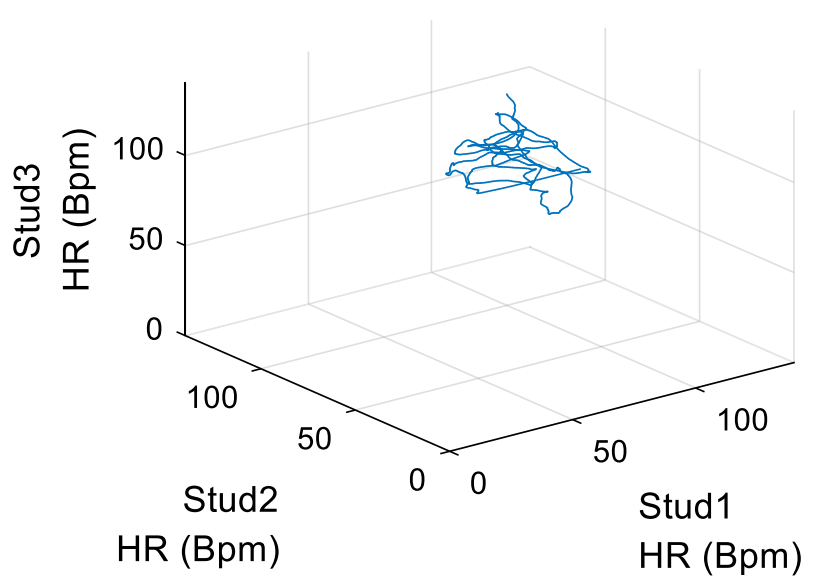

Fig. 2 HR values from three group members represented as a trajectory in a three-dimensional coordinate system 
all the possible discrete states were represented by centroid vectors that form a codebook. This codebook was then used to associate each of the HR triplets with the closest centroid in the three-dimensional space. The state transitions happen when the HR triplet changes enough for the association to change to another centroid. The size of the codebook can be selected appropriately to capture essential dynamics of the system. This leads to a tractable number of possible states and state transitions instead of the infinite number of possible HR triplets and their sequences, thus making state pattern analysis feasible. For the technical details of the analysis see Appendix 1.

The last step of the analysis was combining the video data and the physiological state transitions for the collaborative exam sessions that are the focus of this study. To see how the physiological state transitions occurred temporally in terms of changes in regulation, we created charts that illustrate how these state transitions aligned with adaptive, maladaptive, and on-track sequences.

\section{Results}

\section{(RQ1) what kind of monitoring, in terms of target, valence, phase appears during the collaboration, and to what extent do the groups react to the different types?}

A total of 463 monitoring events were coded across the analyzed 9 groups. Monitoring cognition was the most common event $(n=263)$, followed by monitoring behavior $(n=$ 173). The least common events were monitoring motivation or emotion $(n=27)$, which accounted for $5.83 \%$ of the total monitoring events. Considering the valence of the monitoring events, the results show that there was an even distribution of positive and negative valence. Only monitoring cognition and motivation or emotion were coded for valence; monitoring behavior was considered to have no valence. This is due to the hands-on nature of the task, so most of the monitoring behavior statements were related to positioning or use of the equipment, and it was impossible to distinguish valence in those cases. Figure 3 shows the frequency of the monitoring events for different targets (cognition, motivation or emotion, and behavior) and valence (positive or negative). As for the phase of monitoring, most monitoring events were coded during the task enactment phase $(N=345,74.5 \%)$, in the task definition phase 46 instance of monitoring were coded (9.9\%), in the goals and planning phase $56(12.1 \%)$, while in the adaptation and reflection phase $16(3.46 \%)$ monitoring events were identified.

Next, the reactions that followed the monitoring events were analyzed. A reaction from the group followed $84.5 \%$ of all monitoring events. Table 6 presents how often monitoring events with different targets (cognition, motivation or emotion, behavior) and valence (positive or negative) were followed by a reaction.

\section{(RQ2.1) how do maladaptive, adaptive, and on-track sequences occur during collaboration?}

Based on the valence of the monitoring event, and the group's reaction to the event, three types of sequences were defined: maladaptive, adaptive, and on-track. Maladaptive sequences were scarce in the data $(n=17, f=3.67 \%)$. Adaptive sequences were identified 132 times $(f=$ 


\section{Distribution of monitoring events for valence and target of monitoring}

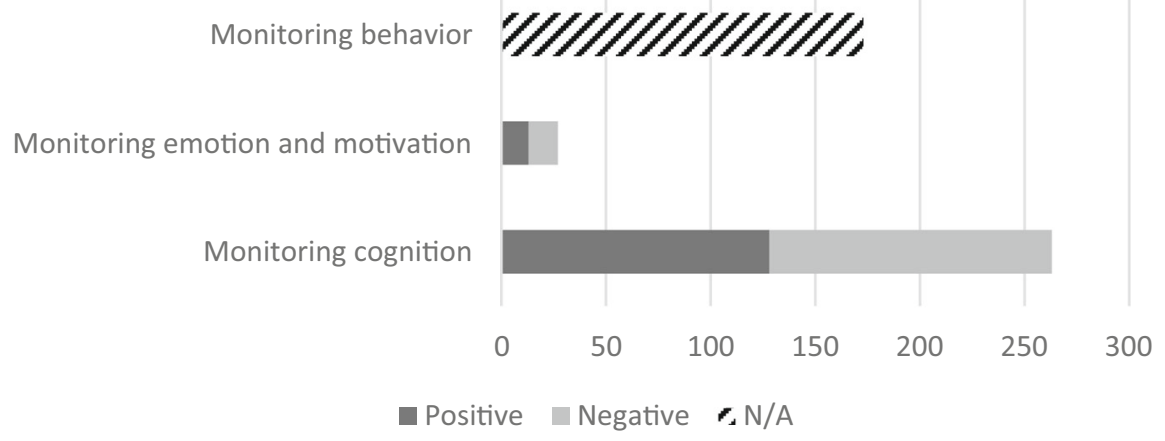

Fig. 3 The distribution of the monitoring events and the monitoring targets

$28.5 \%$ ). On-track sequences were the most common reactions ( $n=313, f=67.7 \%)$, as they included monitoring events with positive valence and all instances of monitoring behavior. See Table 7 for how these sequences were distributed among the groups.

To explore how these sequences of events occurred during collaboration, charts were created for each group showing how they progressed during the collaboration (see Appendix 2 ). Next, the charts were visually inspected, and then categorized into four categories based on the type of sequences that appeared, as well as the phase of regulated learning in which these sequences occurred. Table 8 summarizes the frequencies of the sequences in each category.

The categories differed not only in the frequency of adaptive, maladaptive, and on-track sequences but also in the distribution of the sequences across phases. Table 9 summarizes the key features of each category. In the following, we present one case example from each category.

Table 6 The Frequencies of Reactions to Monitoring Events Characterized by Target and Valence

\begin{tabular}{|c|c|c|c|c|}
\hline & \multirow{2}{*}{$\begin{array}{l}\text { Reaction } \\
\mathrm{f}\end{array}$} & \multirow[b]{2}{*}{$\%$} & \multicolumn{2}{|c|}{ No reaction } \\
\hline & & & $\mathrm{f}$ & $\%$ \\
\hline Monitoring cognition & 243 & $92.40 \%$ & 20 & $7.60 \%$ \\
\hline Negative & 124 & $91.85 \%$ & 11 & $8.15 \%$ \\
\hline Positive & 119 & $92.97 \%$ & 9 & $7.03 \%$ \\
\hline Monitoring emotion and motivation & 19 & $70.37 \%$ & 8 & $29.63 \%$ \\
\hline Negative & 8 & $57.14 \%$ & 6 & $42.86 \%$ \\
\hline Positive & 11 & $84.62 \%$ & 2 & $15.38 \%$ \\
\hline Monitoring behavior & 157 & $90.75 \%$ & 16 & $9.25 \%$ \\
\hline
\end{tabular}


Table 7 Distribution of Maladaptive, Adaptive, and On-Track Sequences Between the Groups

\begin{tabular}{|c|c|c|c|c|c|c|c|}
\hline \multirow[t]{2}{*}{ Group } & \multicolumn{2}{|c|}{ Maladaptive sequences } & \multicolumn{2}{|c|}{ Adaptive sequences } & \multicolumn{2}{|c|}{ On-track sequences } & \multirow{2}{*}{$\begin{array}{l}\text { Total } \\
n\end{array}$} \\
\hline & $\mathrm{f}$ & $\%$ & $\mathrm{f}$ & $\%$ & $\mathrm{f}$ & $\%$ & \\
\hline 1 & 1 & $1.79 \%$ & 10 & $17.86 \%$ & 45 & $80.36 \%$ & 56 \\
\hline 2 & & & 12 & $23.53 \%$ & 39 & $76.47 \%$ & 51 \\
\hline 3 & 6 & $9.23 \%$ & 23 & $35.38 \%$ & 36 & $55.38 \%$ & 65 \\
\hline 4 & 2 & $2.82 \%$ & 41 & $57.75 \%$ & 28 & $39.44 \%$ & 71 \\
\hline 5 & & & 9 & $17.31 \%$ & 43 & $82.69 \%$ & 52 \\
\hline 7 & & & & & 16 & $100.00 \%$ & 16 \\
\hline 8 & 4 & $6.15 \%$ & 20 & $30.77 \%$ & 41 & $63.08 \%$ & 65 \\
\hline 9 & & & 2 & $8.00 \%$ & 23 & $92.00 \%$ & 25 \\
\hline 10 & 4 & $6.45 \%$ & 15 & $24.19 \%$ & 43 & $69.35 \%$ & 62 \\
\hline Total & 17 & $3.67 \%$ & 132 & $28.51 \%$ & 314 & $67.82 \%$ & 463 \\
\hline
\end{tabular}

\section{Category 1 (two groups): Smooth sailing}

This category contained two groups. These two groups completed the task the fastest (group 7: 14 min $41 \mathrm{~s}$; group 9: 23 in $16 \mathrm{~s}$ ), and had the lowest number of monitoring events in total; $95.12 \%$ of the identified sequences were on track. Figure 4 presents how one of the groups in this category (group 7) progressed during their collaborative work.

The members of group 7 started their work by each looking at the task on their iPads. They discussed what equipment they would need (the water cup and laser), and then they briefly started setting up the equipment before agreeing that this seemed easier than they had thought it would be (13:44). They briefly discussed which formula to use, and where to find it, and then they moved onto measuring and calculating. During the task enactment, the target of the monitoring events was judging the accuracy of their result (which they considered correct). At 13:50, they started reflecting on their work, saying that it looked complete and correct. They decided, however, to do the calculation one more time just to be safe. Finally, they ended the session by agreeing that now it was ready, and it "is beautiful".

Table 8 Distribution of Adaptive, Maladaptive, and On-Track Sequences Across Phases of Regulation in the Four Identified Categories

\begin{tabular}{|c|c|c|c|c|c|c|c|c|}
\hline \multirow[t]{2}{*}{ Category } & \multicolumn{2}{|l|}{1} & \multicolumn{2}{|l|}{2} & \multicolumn{2}{|l|}{3} & \multicolumn{2}{|l|}{4} \\
\hline & $\mathrm{f}$ & $\%$ & $\mathrm{f}$ & $\%$ & $\mathrm{f}$ & $\%$ & $\mathrm{f}$ & $\%$ \\
\hline Adaptive & 2 & $4.88 \%$ & 45 & $26.16 \%$ & 24 & $21.05 \%$ & 61 & $44.85 \%$ \\
\hline Task definition & 1 & $2.44 \%$ & 10 & $5.81 \%$ & 2 & $1.75 \%$ & 4 & $2.94 \%$ \\
\hline Goals and planning & & & 1 & $0.58 \%$ & 3 & $2.63 \%$ & 1 & $0.74 \%$ \\
\hline Task enactment & & & 34 & $19.77 \%$ & 18 & $15.79 \%$ & 55 & $40.44 \%$ \\
\hline Adaptation and reflection & 1 & $2.44 \%$ & & & 1 & $0.88 \%$ & 1 & $0.74 \%$ \\
\hline Maladaptive & & & 7 & $4.07 \%$ & 4 & $3.51 \%$ & 6 & $4.41 \%$ \\
\hline Task definition & & & 1 & $0.58 \%$ & & & & \\
\hline Task enactment & & & 6 & $3.49 \%$ & 4 & $3.51 \%$ & 6 & $4.41 \%$ \\
\hline On-track & 39 & $95.12 \%$ & 120 & $69.77 \%$ & 86 & $75.44 \%$ & 69 & $50.74 \%$ \\
\hline Task definition & 1 & $2.44 \%$ & 20 & $11.63 \%$ & 4 & $3.51 \%$ & 3 & $2.21 \%$ \\
\hline Goals and planning & 7 & $17.07 \%$ & 14 & $8.14 \%$ & 20 & $17.54 \%$ & 10 & $7.35 \%$ \\
\hline Task enactment & 24 & $58.54 \%$ & 85 & $49.42 \%$ & 60 & $52.63 \%$ & 53 & $38.97 \%$ \\
\hline Adaptation and reflection & 7 & $17.07 \%$ & 1 & $0.58 \%$ & 2 & $1.75 \%$ & 3 & $2.21 \%$ \\
\hline Total & 41 & $100.00 \%$ & 172 & $100.00 \%$ & 114 & $100.00 \%$ & 136 & $100.00 \%$ \\
\hline
\end{tabular}


Table 9 Overview of Key Features of the Four Identified Categories

\begin{tabular}{|c|c|c|c|}
\hline Category 1 & Category 2 & Category 3 & Category 4 \\
\hline "Smooth sailing" & "What is our task again?" & $\begin{array}{l}\text { "So, how should we } \\
\text { proceed?" }\end{array}$ & "What are we doing?" \\
\hline $\begin{array}{l}\text { - Shortest time to } \\
\text { complete task } \\
\text { - Highest frequency of } \\
\text { on-track sequences }\end{array}$ & $\begin{array}{l}\text { - Sequences in the task } \\
\text { definition phase more } \\
\text { common than in all the } \\
\text { categories combined }\end{array}$ & $\begin{array}{l}\text { - Sequences in the goals and } \\
\text { planning phase more } \\
\text { common than in all the } \\
\text { categories combined }\end{array}$ & $\begin{array}{l}\text { - Longest time to } \\
\text { complete the task } \\
\text { - Least amount of } \\
\text { on-track sequences, }\end{array}$ \\
\hline $\begin{array}{c}\text { Lowest frequency of } \\
\text { monitoring events }\end{array}$ & $\begin{array}{l}\text { - Groups returned to task } \\
\text { definition throughout the } \\
\text { session }\end{array}$ & $\begin{array}{l}\text { - Groups returned to the goals } \\
\text { and planning phase } \\
\text { frequently throughout the } \\
\text { session }\end{array}$ & $\begin{array}{l}\text { highest frequency of } \\
\text { adaptive regulation } \\
\text { - Most sequences in the } \\
\text { task enactment phase }\end{array}$ \\
\hline
\end{tabular}

\section{Category 2 (three groups): What is our task again?}

There were three groups in category 3, with an average task completion time of $25 \min 3 \mathrm{~s}$ $(S D=34 \mathrm{~s})$. When all coded sequences in this category were considered, $18.02 \%$ occurred during the task definition phase, compared to $9.94 \%$ in all the categories combined. Figure 5 shows how one of the groups in this category (group 2) progressed during their collaborative work, and how they frequently returned to the task definition phase throughout the session.

This group spent their first 5 min (8:57-9:02) going back and forth between discussing what was required for the task and setting up the equipment. At one point (9:01), they agreed that if use of the laser was allowed, then the task would be easy. This was followed by the group adjusting the lasers and performing different calculations. The peaks representing adaptive sequences occurred when the monitoring cognition revealed a problem with the calculation (e.g., at 9:07: "hmm...there is something wrong now"), which was followed by a group discussion. At 9:08, they went back to the task definition again, and discussed what they were supposed to write down, followed by 11 min of intense work, during which they went over their thought process again, checked the calculations, and wrote them down on the paper. At the end (9:22), they returned to the task definition, checked the requirements, and added a few more things on the paper, before reading the task definition again and concluding that they were done.

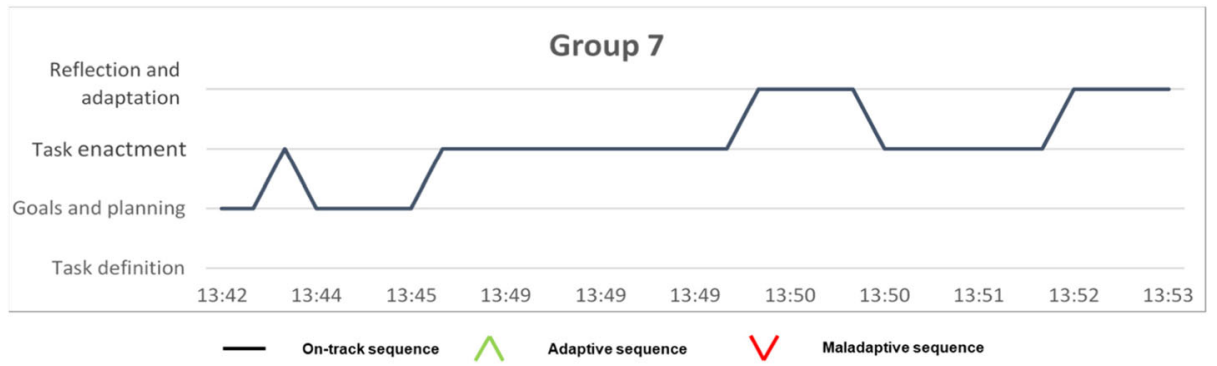

Fig. 4 Timeline of on-track, maladaptive, and adaptive sequences in different phases of regulation in group 7. Straight lines represent on-track sequences. There are only on-track sequences in this example 


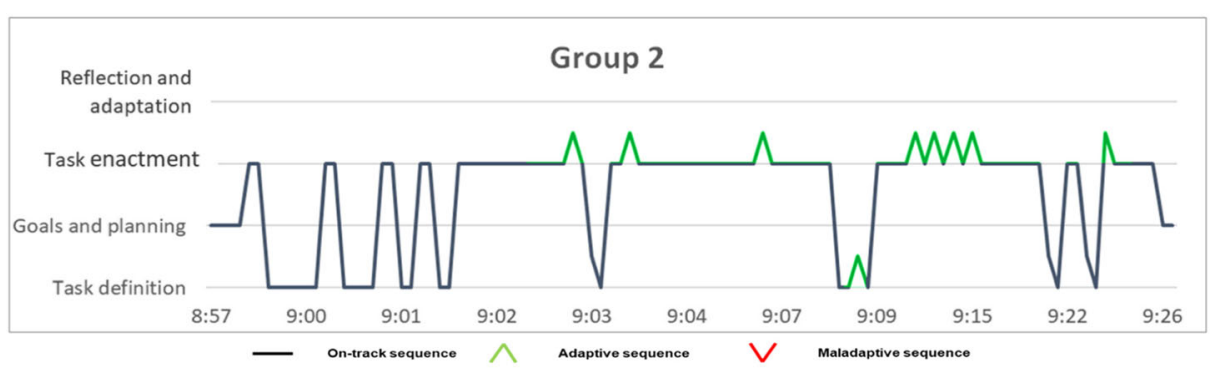

Fig. 5 Timeline of on-track, maladaptive, and adaptive sequences in different phases of regulation in group 2. Straight lines represent on-track sequences, and peaks represent adaptive regulation

\section{Category 3 (two groups): So, how should we proceed?}

This category included two groups that can be characterized by returning to the goals and planning phase frequently throughout the session, resulting in $20.17 \%$ of the coded sequences being in this phase (compared to $12.1 \%$ in all the groups). This category had the longest task completion time (group 5: $39 \mathrm{~min} 53 \mathrm{~s}$; group 10: $36 \mathrm{~min} 10 \mathrm{~s}$ ). Figure 6 shows the timeline of group 10.

Group 10 started by briefly checking the task to see what equipment they needed, and then they switched between discussing how to set up the equipment and setting it up. At 13:06, they turned on the laser, and tried to turn it so that they saw the angle they needed. At 13:08, they returned to planning, and decided that they also needed to start drawing the required picture of the experimental setup. In the next 24 min (until 13:32), they struggled with deciding which angle they needed to measure, and which formula to use for the calculations. They also discussed whether they needed to take the plastic cup into account in the calculations. Whenever they got a result, they compared it to the correct one, and realized that it was not close enough, which was followed by renewed discussion about what to do differently. In this group, the maladaptive sequences were the result of different group members monitoring their negative emotions, which were ignored by the group. At 13:32, one of the group members used the correct formula, and got the correct result, after which the group went back to reading the task instructions to check if they had all the required parts on the paper. At the end, they finished by reflecting on their work and their emotions.

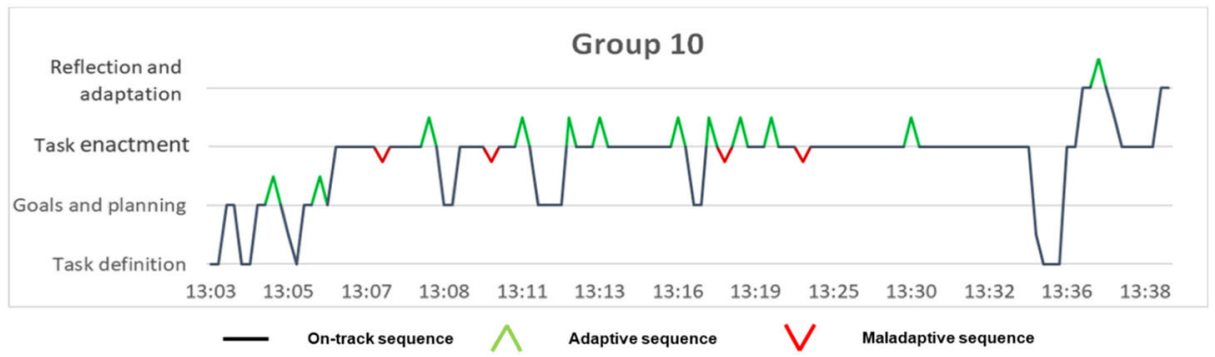

Fig. 6 Timeline of on-track, maladaptive, and adaptive sequences in different phases of regulation in group 10. Straight lines represent on-track sequences, peaks represent adaptive regulation, and small downward dips represent maladaptive behavior 


\section{Category 4 (two groups): What are we doing?}

Groups in category 4 were characterized by frequently engaging in adaptive regulation during the task enactment phase. These groups had the least amount of on-track behavior $(50.74 \%$ of all identified sequences), and the highest frequency of adaptive regulation (44.85\%). Their task completion time was close to the mean completion time across groups (group 4: 26 min $17 \mathrm{~s}$; group 8: $30 \mathrm{~min}, 9 \mathrm{~s}$ )). Figure 7 shows the timeline of group 4, who started their work by briefly reading the task and summing it up together. Within $30 \mathrm{~s}$, they moved on to the task enactment phase, looking up formulas in the book and discussing which one to use.

The members of group 4 frequently expressed uncertainty about the chosen formulas, which was followed by more browsing of the book and new calculations. At 9:13, they briefly revised their plan, thinking that they should have done the measurements first without water in the cup. After trying this way, they soon realized that they did not need to do that. They returned to making hands-on adjustments to the laser, and trying to figure out why the result they were getting was not correct. After some adjustments, the group tried the calculations with new values, and they got a better result (9:16). They then read the task definition again together, and checked whether there was something more to do. They wrote down the calculations, often realizing that they needed to be more specific, and identified the angles used in the calculations in the drawing as well. Finally, they concluded that their results were accurate, read the task again, and then handed in their paper.

\section{(RQ2.2) what is the relation between adaptive and maladaptive sequences in the groups' physiological state transitions?}

The distribution of these sequences, as well as the frequency of the physiological state transitions during the session, varied among the groups (Table 10).

To determine the relation between physiological state transitions and adaptive, maladaptive, and on-track sequences, the frequency of these events was calculated for every minute for each group, resulting in total of 79 min for the three groups for whom physiological state analysis was available. Figure 8 illustrates a temporal comparison of the three groups, including the adaptive, maladaptive, and on-track sequences, and the physiological state transitions, where the occurrence of physiological state transitions is marked with a dot. These groups were

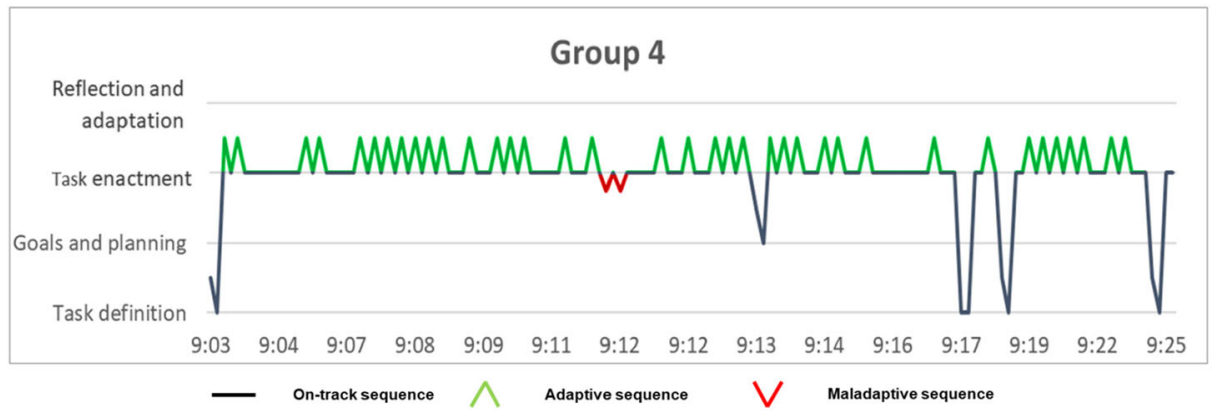

Fig. 7 Timeline of on-track, maladaptive, and adaptive sequences in different phases of regulation in group 10 . Straight lines represent on-track sequences, peaks represent adaptive regulation, and small downward dips represent maladaptive behavior 
Table 10 Distribution of On-Track, Adaptive, and Maladaptive Behavior Sequences, and the Frequency of Physiological State Transitions During the Session

\begin{tabular}{lllll}
\hline Group & Maladaptive & Adaptive & On-track & Physiological state transition \\
\hline 1 & 1 & 10 & 45 & 21 \\
2 & 0 & 12 & 39 & 17 \\
4 & 2 & 41 & 28 & 7 \\
\hline
\end{tabular}

categorized to represent "What is our task again?" (groups 1 and 2) and "What are we doing?" (group 4).

To assess the relationship between the number of physiological state transitions and the ontrack, adaptive, and maladaptive sequences, a Spearman's rank-order correlation was run, as the data were not normally distributed. There was a positive correlation between the physiological state transitions and the on-track sequences $\left(r_{s}=.23, p=.041\right)$.

\section{Group 1}
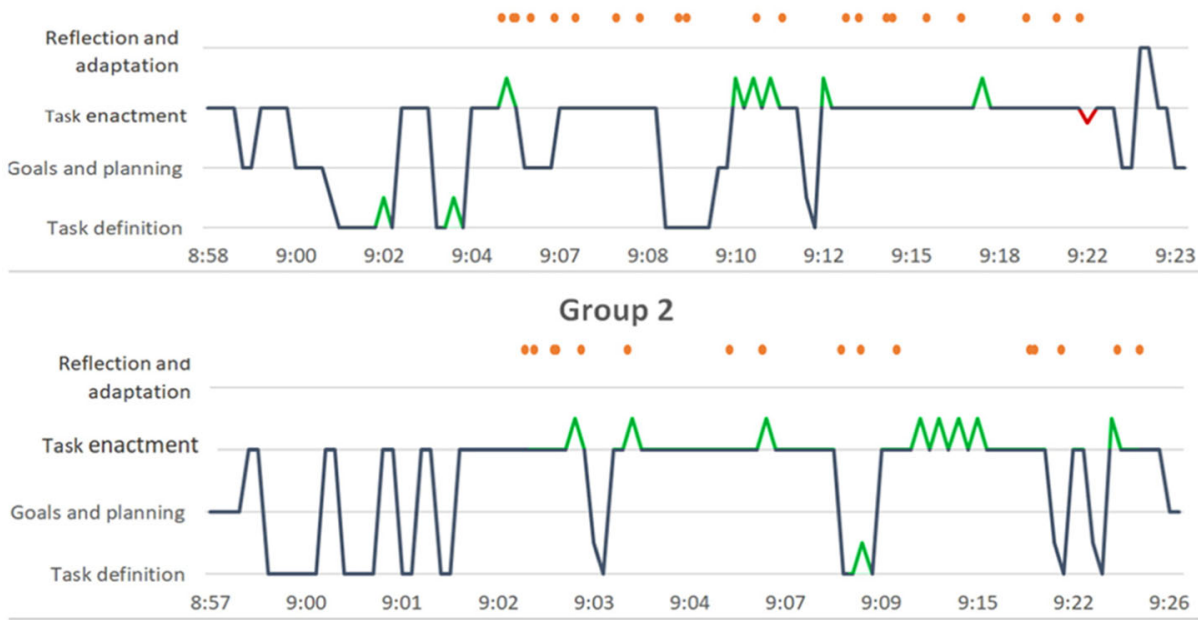

Group 4

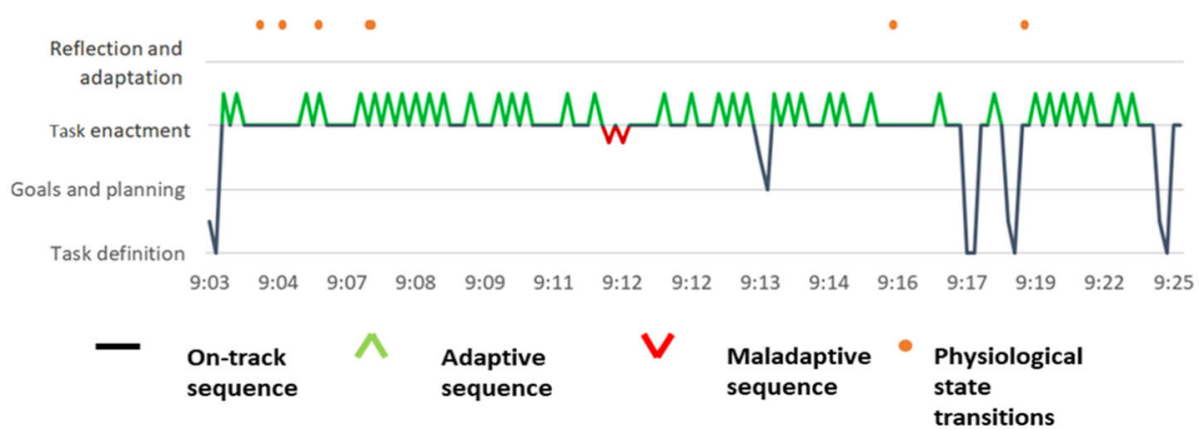

Fig. 8 Frequency of physiological state transitions and adaptive and maladaptive sequences over the course of the collaborative exam in two groups 


\section{Discussion}

The aim of this study was to investigate how monitoring sequences can indicate adaptive regulation or maladaptive behavior, and how these sequences are related to group-level physiological states. First, the types of monitoring used by the groups was described in terms of the monitoring target and valence. The results indicated that monitoring cognition was the most common, followed by monitoring behavior. Monitoring motivation or emotion were scarce in the data. A similar finding was reported in the Koivuniemi et al. (2018) study that explored students' interpretation of challenges faced during collaboration, and found that students were less likely to recognize motivational and emotional learning challenges. In the present study context, the exam situation could also explain the lack of monitoring emotions. During an exam situation, the primary goal is completing the task, and cognitive processes can be used to regulate emotions (see the task-focusing processes in Schutz and Davis 2000). Looking at the reaction of the group to monitoring events, monitoring cognition and behavior were followed by a reaction in most cases. Although monitoring motivation or emotion were scarce in the data, it is notable that this type of monitoring with negative valence had the lowest reaction rate.

The valence of monitoring, and the reaction or lack of reaction to it, was used to determine the adaptive, maladaptive, and on-track sequences. On-track sequences were found to be the most common, followed by adaptive and maladaptive sequences. This result can be explained, as all groups completed the task and received high grades, and adaptive regulation skills are known to be linked with higher performance (Järvelä et al. 2013; J. Zheng et al. 2019).

Second, the temporality of adaptive, maladaptive, and on-track sequences occur during collaboration, was analyzed. Using a data driven approach, results showed that the groups' progress could be described as belonging to one of four categories. In the following we discuss how they relate to previous findings. Groups in the first category ("smooth sailing") had a high percentage of on-track sequences progressing according to the self-regulated learning cycle, and rarely returned to a previous phase. Returning to a previous phase is a way to update task definition, goals, or plans if needed (Winne and Perry 2000). These groups did not have a need to regulate their learning, as evidenced by the low frequency of monitoring events with negative valence.

Groups in the second ("What is our task again?") and third ("So how should we proceed?) categories returned to the task definition or goals and planning phase. Returning to the task definition or goals and planning phases can be interpreted as a sign of metacognitive activation. This is in accordance with Sonnenberg and Bannert (2015), who found that groups that receive metacognitive prompts engage in a higher number of regulation loops.

Groups in the fourth category ("What are we doing?") stayed mostly in the task enactment phase, where they exhibited a high frequency of adaptive sequences in response to monitoring events with negative valence. Looking at behavioral patterns during collaborative learning, Zheng and $\mathrm{Yu}$ (2016) found that high-achievement groups monitored and controlled their group progress more often than low-achievement groups, and changed their behavior more often.

In this study, the groups' whole session could be categorized into one of the four categories, as there was only one task and the task completion time was limited. It can be hypothesized that if the task was more complex and had a longer completion time, one group could go through sections of different categories. 
Last, the relation between adaptive, maladaptive, and on-track sequences and group-level physiological state transitions was analyzed. Results show that the groups experienced more physiological state transitions when they were on track compared to when they used adaptive regulation or maladaptive behavior. This finding can indicate that when groups progress smoothly, i.e., there is no or an infrequent need for regulation, then they undergo various different physiological states. That is, physiological state changes are indicators of the progress with the task. However, when the groups did not progress as smoothly with the task, and there was a need for regulation, the physiological state transitions did not change, which actually can inform an extensive need for metacognitive monitoring, and the need to adapt the regulation. A possible explanation for this finding is that facing challenges, especially in an exam situation can constitute a high stress situation, and heart rate is elevated under stress. An earlier study focusing on learning from text found that learners experienced a marked increase in heart rate during testing phase compared to reading (Scrimin et al. 2018). Considering group level physiological states, if all group members had continuously elevated heart rate, then the group level physiological states would be stable, and there would be no transitions. However, these findings need further examination of how physiological state transitions relate to the groups' progress with the task, considering both regulatory processes as well as stress level and cognitive load, which can both affect heart rate.

This study has some limitations. First, the sample size was small, and there was an imbalance in the gender of the participants. A cross-country study showed that gender influences arithmetic performance in certain contexts (Shen et al. 2016). However, it allowed us to perform in a detailed qualitative analysis, which would have not been possible with larger number of participants. In addition, all the participants were high-performing students, although some evidence of maladaptive behavior was found. The maladaptive behavioral sequence had a narrow definition in this study, which could be extended in subsequent, experimental studies to cover other aspects, such as inaccuracy of monitoring. Future studies should examine how on-track, adaptive, and maladaptive sequences occur in low-performing groups, and ultimately, how the temporality of these sequences can be used to predict group learning progress. Future studies should also include tasks with longer expected completion time, so groups' possible variation of the four categories of progress introduced in this study can be studied over time.

Some of the limitations includes the usage of heart rate data. Despite the technological advancements, it is difficult to unobtrusively capture good-quality data in a real-life context, especially when focusing on a group. However, we still believe that for true regulation or need for metacognition to occur, the learning tasks should be authentic, and be meaningful for the students (Järvenoja et al. 2019).

\section{Conclusions}

The present study indicated that by looking at three different dimensions of monitoring, namely the target, valence, and phase, and what follows after, we can identify the sequences of regulation that are indicative of adaptive or maladaptive behavior. Based on the data in this study, physiological state transitions are markedly more frequent in sessions when groups are on track, and control their learning process less. That is, physiological state transitions that can be tracked by using unobtrusive data have the potential to be used as one data channel when investigating regulation of learning. 
We conclude that multimodal methods, such as psychophysiological measures combined with video data, might have the potential to contribute to theoretical advancements when studying regulated learning. Reimann (2019) argues, that in order to have a fully processoriented view, we should take into account not only events that occur, but also what other events it triggers. This study makes three contributions that are in line with this call for research: first, it empirically identified instances of groups' need for regulation by taking into account the valence of monitoring. Second, it provided an empirical framework based on the theory for how to identify adaptive regulation or maladaptive behavior from the process data using monitoring events and groups' reaction to them. Third, the study investigated the relation between shifts in group metacognitive activity marked by adaptive, maladaptive and on-track sequences and transitions in group-level physiological states.

Studies using multimodal data in SRL research are increasing (See e.g. Azevedo and Gašević 2019), but more empirical work is needed to confirm their methodological relevancy for theoretical progress in the field of regulated learning.

Acknowledgments Research funded by the Finnish Academy, Project no. 275440.

The Oulu University LeaF research infrastructure was used in the data collection.

Funding Information Open access funding provided by University of Oulu including Oulu University Hospital.

\section{Compliance with ethical standards}

Conflict of interest The authors declare that there is no conflict of interest.

\section{Appendix 1}

In the following, we describe the process of applying VQ to the HR triplets in detail. The first step was to create a training set. The whole set of data collected throughout the course - not only the exam sessions in question - was used, from all the sessions where all three students were present during the session, and the sessions provided complete data. We obtained a k-by-M matrix, where $\mathrm{k}$, the number of elements in the training vector, was 3 (with HR measurements as vector elements from three students), and $\mathrm{M}$, the number of training vectors, equaled 60,227.

The second step was to train a quantizer codebook. This was achieved by using the MATLAB VQDTool (MathWorks 2018), where the number of levels was set at eight. The number of levels used in the vector quantizer was chosen by visually examining the images of the HR trajectories. For the initial codebook, eight random training vectors were autogenerated. Linde et al. (1980) proposed constructing the initial codebook by choosing the codewords randomly from the training data. The resulting codebook can be considered to have a physical meaning, because it results from the HR values in the training set.

In this study, MATLAB dsp.VectorQuantizerEncoder (MathWorks 2018) was used to create a vector quantizer encoder object to find the indices of the nearest code words based on Euclidean distances for each session and group individually. A new representation for the data was created, consisting of vector quantized states. To capture the change in the dynamic system of the groups, the timestamps when the identified states changed were extracted. In the analysis, these time instants are referred as physiological state transitions. 


\section{Appendix 2}

\section{Category 1 - "Smooth Sailing"}
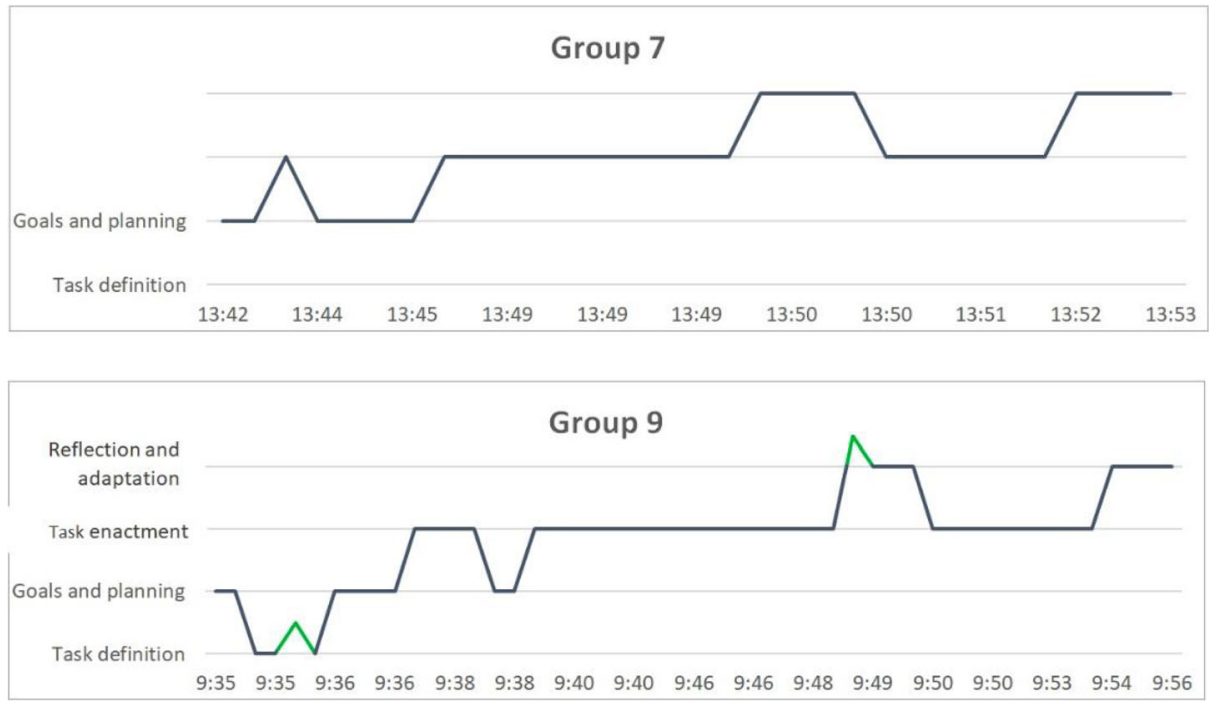


\section{Category 2 - "What is our task again?"}
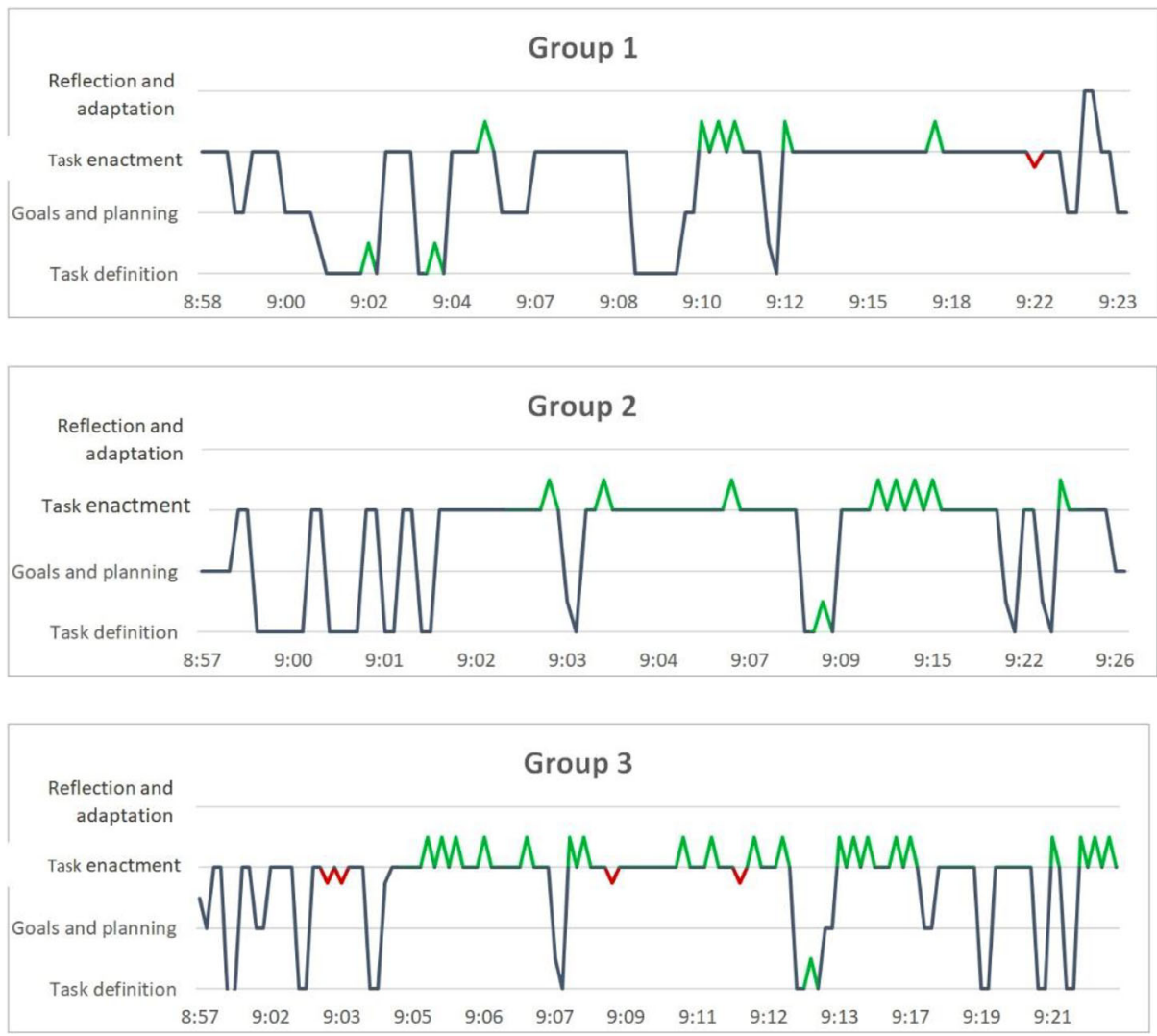
Category 3 - "So how should we do this?"
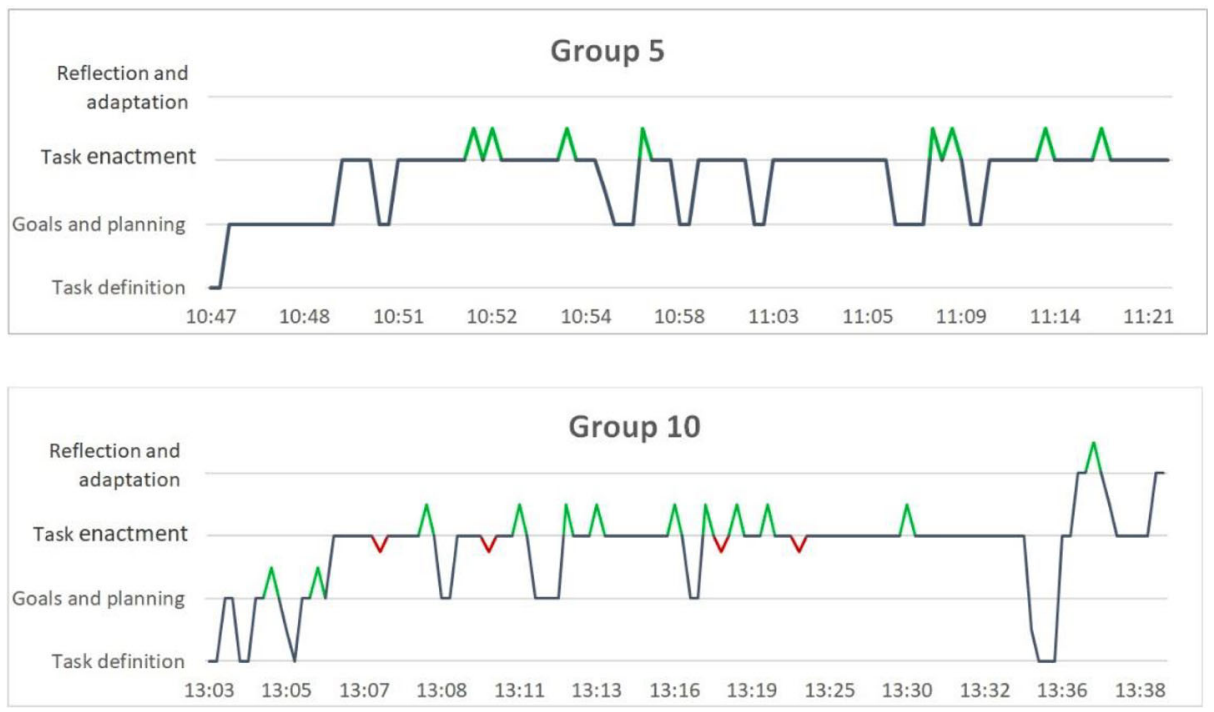

Category 4 - "So how should we do this?"
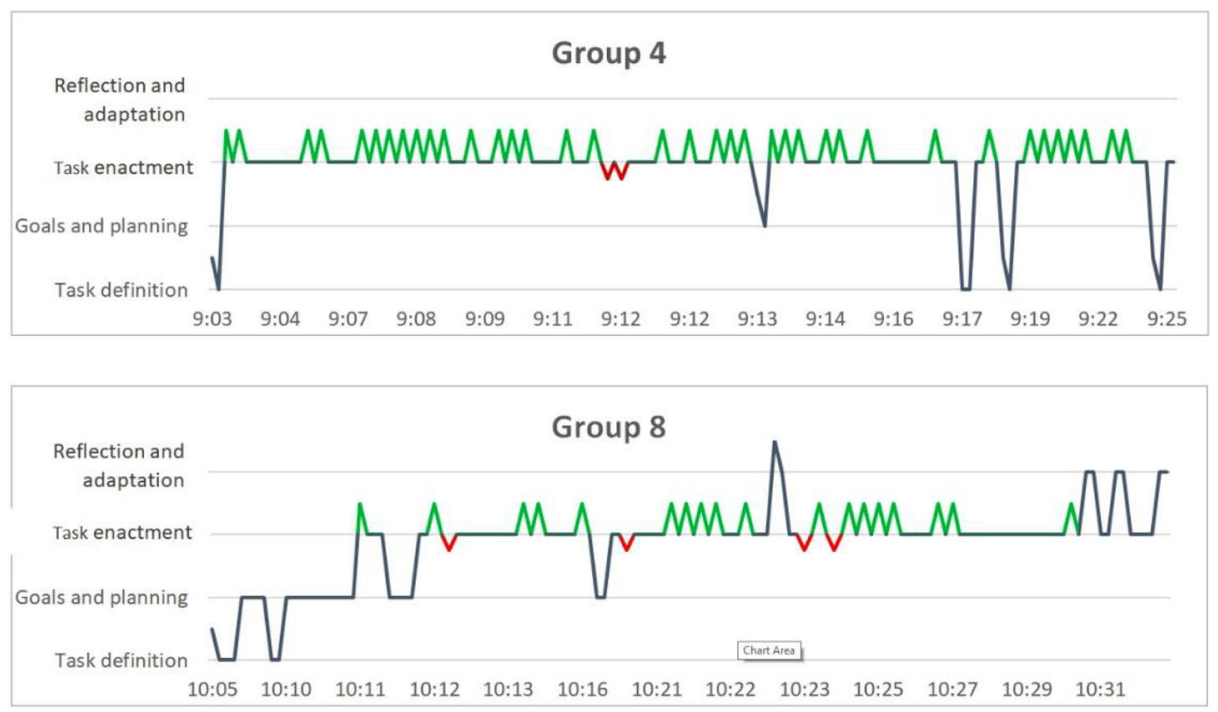
Open Access This article is licensed under a Creative Commons Attribution 4.0 International License, which permits use, sharing, adaptation, distribution and reproduction in any medium or format, as long as you give appropriate credit to the original author(s) and the source, provide a link to the Creative Commons licence, and indicate if changes were made. The images or other third party material in this article are included in the article's Creative Commons licence, unless indicated otherwise in a credit line to the material. If material is not included in the article's Creative Commons licence and your intended use is not permitted by statutory regulation or exceeds the permitted use, you will need to obtain permission directly from the copyright holder. To view a copy of this licence, visit http://creativecommons.org/licenses/by/4.0/.

\section{References}

Ahonen, L., Cowley, B. U., Hellas, A., \& Puolamäki, K. (2018). Biosignals reflect pair-dynamics in collaborative work: EDA and ECG study of pair-programming in a classroom environment. Scientific Reports, 8, 1-16. https://doi.org/10.1038/s41598-018-21518-3.

Anderman, E. M., \& Midgley, C. (2002). Methods for studying goals, goal structures, and patterns of adaptive learning. In Goals, goal structures, and patterns of adaptive learning (pp. 1-20). Mahwah: Erlbaum.

Azevedo, R. (2009). Theoretical, conceptual, methodological, and instructional issues in research on metacognition and self-regulated learning: A discussion. Metacognition and Learning, 4(1), 87-95. https://doi. org/10.1007/s11409-009-9035-7.

Azevedo, R. (2015). Defining and measuring engagement and learning in science: Conceptual, theoretical, methodological, and analytical issues. Educational Psychologist, 50(1), 84-94. https://doi.org/10.1080 /00461520.2015.1004069.

Azevedo, R., \& Gašević, D. (2019). Analyzing multimodal multichannel data about self-regulated learning with advanced learning technologies: Issues and challenges. Computers in Human Behavior, 96, 207-210. https://doi.org/10.1016/j.chb.2019.03.025.

Azevedo, R., Moos, D. C., Johnson, A. M., \& Chauncey, A. D. (2010). Measuring cognitive and metacognitive regulatory processes during hypermedia learning: Issues and challenges. Educational Psychologist, 45(4), 210-223. https://doi.org/10.1080/00461520.2010.515934.

Azevedo, R., \& Witherspoon, A. (2009). Self-regulated learning with hypermedia. In D. J. Hacker, J. Dunlosky, \& A. C. Graesser (Eds.), Handbook of metacognition in education (pp. 319-339). New York: Routledge.

Bakhtiar, A., Webster, E. A., \& Hadwin, A. F. (2017). Regulation and socio-emotional interactions in a positive and a negative group climate. Metacognition and Learning, 13(3), 57-90. https://doi.org/10.1007/s11409-017-9178-x.

Barron, B. (2003). When smart groups fail. The Journal of the Learning Sciences, 12(3), 307-359. https://doi. org/10.1207/S15327809JLS1203.

Ben-Eliyahu, A., \& Bernacki, M. L. (2015). Addressing complexities in self-regulated learning: A focus on contextual factors, contingencies, and dynamic relations. Metacognition and Learning, 10(1), 1-13. https://oi.org/10.1007/s11409-015-9134-6.

Binbasaran Tuysuzoglu, B., \& Greene, J. A. (2014). An investigation of the role of contingent metacognitive behavior in self-regulated learning. Metacognition and learning, 77-98. https://doi.org/10.1007/s11409-014-9126-y.

de Bruin, A. B. H., \& van Gog, T. (2012). Improving self-monitoring and self-regulation: From cognitive psychology to the classroom. Learning and Instruction, 22(4), 245-252. https://doi.org/10.1016/j. learninstruc.2012.01.003.

Deekens, V. M., Greene, J. A., \& Lobczowski, N. G. (2018). Monitoring and depth of strategy use in computerbased learning environments for science and history, 63-79. https://doi.org/10.1111/bjep.12174.

Dindar, M., Alikhani, I., Malmberg, J., Järvelä, S., \& Seppänen, T. (2019). Examining shared monitoring in collaborative learning: A case of a recurrence quantification analysis approach. Computers in Human Behavior, (April). 10.1016/j.chb.2019.03.004

Efklides, A. (2011). Interactions of metacognition with motivation and affect in self-regulated learning: The MASRL model. Educational Psychologist, 46(1), 6-25. https://doi.org/10.1080/00461520.2011.538645.

Elkins, A. N., Muth, E. R., Hoover, A. W., Walker, A. D., Carpenter, T. L., \& Switzer, F. S. (2009). Physiological compliance and team performance. Applied Ergonomics, 40(6), 997-1003. https://doi.org/10.1016/j. apergo.2009.02.002.

Fransen, J., Kirschner, P. A., \& Erkens, G. (2011). Mediating team effectiveness in the context of collaborative learning: The importance of team and task awareness. Computers in Human Behavior, 27(3), 1103-1113. https://doi.org/10.1016/j.chb.2010.05.017.

Gersho, A., \& Gray, R. M. (1991). Vector quantization and signal compression. Norwell: Kluwer Academic.

Gray, R. M. (1984). Vector quantization. IEEE ASSP Magazine., 1, 4-29. https://doi.org/10.1109 /MASSP.1984.1162229. 
Griffin, T. D., Wiley, J., \& Salas, C. R. (2013). Supporting effective self-regulated learning: The critical role of monitoring. In: International handbook of metacognition and learning technologies (Vol. 28, pp. 19-35). New York: Springer-Verlag. https://doi.org/10.1007/978-1-4419-5546-3.

Haataja, E., Malmberg, J., \& Järvelä, S. (2018). Monitoring in collaborative learning: Co-occurrence of observed behavior and physiological synchrony explored. Computers in Human Behavior, 87(October), 337-347. https://doi.org/10.1016/j.chb.2018.06.007.

Hadwin, A. F., Bakhtiar, A., \& Miller, M. (2018a). Challenges in online collaboration: Effects of scripting shared task perceptions. International Journal of Computer-Supported Collaborative Learning, 1-29. https://doi. org/10.1007/s11412-018-9279-9.

Hadwin, A. F., Järvelä, S., \& Miller, M. (2018b). Self-regulation, co-regulation and shared regulation in collaborative learning environments. In D. H. Schunk \& J. A. Greene (Eds.), Handbook of self-regulation of learning and performance (2nd ed., pp. 83-106). New York: Routledge.

Harkin, B., Webb, T. L., Chang, B. P. I., Prestwich, A., Conner, M., Kellar, I., Benn, Y., \& Sheeran, P. (2016). Does monitoring goal progress promote goal attainment? A meta-analysis of the experimental evidence Benjamin. Psychological Bulletin, 142(2), 198-229.

Hilpert, J. C., \& Marchand, G. C. (2018). Complex systems research in educational psychology: Aligning theory and method. Educational Psychologist, 53(3), 185-202. https://doi.org/10.1080/00461520.2018.1469411.

Janssen, J., Erkens, G., Kirschner, P. a., \& Kanselaar, G. (2010). Task-related and social regulation during online collaborative learning. Metacognition and Learning, 7(1), 25-43. https://doi.org/10.1007/s11409-010-9061-5.

Järvelä, S., \& Hadwin, A. F. (2013). New frontiers: Regulating learning in CSCL. Educational Psychologist, 48(1), 25-39. https://doi.org/10.1080/00461520.2012.748006.

Järvelä, S., Järvenoja, H., Malmberg, J., \& Hadwin, A. F. (2013). Exploring socially shared regulation in the context of collaboration. Journal of Cognitive Education and Psychology., 12, 267-286. https://doi. org/10.1891/1945-8959.12.3.267.

Järvelä, S., Kirschner, P. A., Panadero, E., Malmberg, J., Phielix, C., Jaspers, J., Koivuniemi, M., \& Järvenoja, H. (2015). Enhancing socially shared regulation in collaborative learning groups: Designing for CSCL regulation tools. Educational Technology Research and Development, 63(1), 125-142. https://doi.org/10.1007 /s11423-014-9358-1.

Järvelä, S., Malmberg, J., Haataja, E., Sobocinski, M., \& Kirschner, P. A. (2019). What multimodal data can tell us about the students ' regulation of their learning process ? Learning and Instruction, (March), 101203. https://doi.org/10.1016/j.learninstruc.2019.04.004.

Järvenoja, H., \& Järvelä, S. (2009). Emotion control in collaborative learning situations: Do students regulate emotions evoked by social challenges? The British Journal of Educational Psychology, 79(3), 463-481. https://doi.org/10.1348/000709909X402811.

Järvenoja, H., Malmberg, J., Järvelä, S., Näykki, P., \& Kontturi, H. (2019). Investigating students' situationspecific emotional state and motivational goals during a learning project within one primary school classroom. Learning: Research and Practice. https://doi.org/10.1080/23735082.2018.1554821.

Khosa, D. K., \& Volet, S. E. (2014). Productive group engagement in cognitive activity and metacognitive regulation during collaborative learning: Can it explain differences in students' conceptual understanding? Metacognition and Learning, 9(3), 287-307. https://doi.org/10.1007/s11409-014-9117-z.

Koivuniemi, M., Järvenoja, H., \& Järvelä, S. (2018). Teacher education students' strategic activities in challenging collaborative learning situations. Learning, Culture and Social Interaction, 19(December), 109-123. https://doi.org/10.1016/j.lcsi.2018.05.002.

Kreijns, K., Kirschner, P. A., \& Jochems, W. (2003). Identifying the pitfalls for social interaction in computersupported collaborative learning environments: A review of the research. Computers in Human Behavior, 19(3), 335-353. https://doi.org/10.1016/S0747-5632(02)00057-2.

Kreijns, K., Kirschner, P. A., \& Vermeulen, M. (2013). Social aspects of CSCL environments: A research framework. Educational Psychologist, 48(4), 229-242. https://doi.org/10.1080/00461520.2012.750225.

Kwon, K., Liu, Y. H., \& Johnson, L. P. (2014). Group regulation and social-emotional interactions observed in computer supported collaborative learning: Comparison between good vs. poor collaborators. Computers and Education, 78, 185-200. https://doi.org/10.1016/j.compedu.2014.06.004.

Linde, Y., Buzo, A., \& Gray, R. M. (1980). An algorithm for vector quantizer design. IEEE Transactions on Communications, 28, 84-95. https://doi.org/10.1109/TCOM.1980.1094577.

Malmberg, J., Järvelä, S., Holappa, J., Haataja, E., Huang, X., \& Siipo, A. (2018). Going beyond what is visible: What multichannel data can reveal about interaction in the context of collaborative learning? Computers in human behavior, (June), 1-11. https://doi.org/10.1016/j.chb.2018.06.030.

Malmberg, J., Järvenoja, H., \& Järvelä, S. (2010). Tracing elementary school students' study tactic use in gStudy by examining a strategic and self-regulated learning. Computers in Human Behavior, 26(5), 1034-1042. https://doi.org/10.1016/j.chb.2010.03.004. 
Malmberg, J., Järvenoja, H., \& Järvelä, S. (2013). Patterns in elementary school students' strategic actions in varying learning situations. Instructional Science, 41(5), 933-954. https://doi.org/10.1007/s11251-012-9262-1.

Martin, A. J. (2007). Examining a multidimensional model of student motivation and engagement using a construct validation approach. British Journal of Educational Psychology, 77(2), 413-440. https:/doi. org/10.1348/000709906X118036.

McHugh, M. L. (2012). Interrater reliability: The kappa statistic. Biochemia Medica, 22(3), $276-282$. http://www.ncbi.nlm.nih.gov/pmc/articles/PMC3900052/

Montague, E., Xu, J., \& Chiou, E. (2014). Shared experiences of technology and trust: An experimental study of physiological compliance between active and passive users in technology-mediated collaborative encounters. IEEE Transactions on Human-Machine Systems, 44(5), 614-624. https://doi.org/10.1109 /THMS.2014.2325859.

Mudrick, N. V., Azevedo, R., \& Taub, M. (2018). Integrating metacognitive judgments and eye movements using sequential pattern mining to understand processes underlying multimedia learning. Computers in Human Behavior, 96(December 2016), 223-234. https://doi.org/10.1016/j.chb.2018.06.028.

Nelson, T. O., \& Narens, L. (1994). Why investigate metacognition? In Metacognition: Knowing about knowing (pp. 1-25). Cambridge: The MIT Press.

Noroozi, O., Alikhani, I., Järvelä, S., Kirschner, P. A., Juuso, I., \& Seppänen, T. (2018). Multimodal data to design visual learning analytics for understanding regulation of learning. Computers in Human Behavior, 100, 298-304. https://doi.org/10.1016/j.chb.2018.12.019.

Noroozi, O., Biemans, H. J. A., Weinberger, A., Mulder, M., \& Chizari, M. (2013). Scripting for construction of a transactive memory system in multidisciplinary CSCL environments. Learning and Instruction, 25, 1-12. https://doi.org/10.1016/j.learninstruc.2012.10.002.

Pieschl, S., Stahl, E., Murray, T., \& Bromme, R. (2012). Is adaptation to task complexity really beneficial for performance? Learning and Instruction, 22(4), 281-289. https://doi.org/10.1016/j.learninstruc.2011.08.005.

Pijeira-Díaz, H. J., Drachsler, H., Järvelä, S., \& Kirschner, P. A. (2016). Investigating collaborative learning success with physiological coupling indices based on electrodermal activity. In Proceedings of the sixth international conference on Learning Analytics \& Knowledge - LAK '16 (pp. 64-73). Edinburgh: ACM. https://doi.org/10.1145/2883851.2883897.

Pijeira-Díaz, H. J., Drachsler, H., Kirschner, P. A., \& Järvelä, S. (2018). Profiling sympathetic arousal in a physics course: How active are students? Journal of Computer Assisted Learning, 34(4), 397-408. https://oi. org/10.1111/jcal.12271.

Pijeira-Díaz, H. J., Drachsler, H., Järvelä, S., \& Kirschner, P. A. (2019). Sympathetic arousal commonalities and arousal contagion during collaborative learning: How attuned are triad members? Computers in Human Behavior, 92(May), 188-197. https://doi.org/10.1016/j.chb.2018.11.008.

Pintrich, P. R., Smith, D. A. F., Garcia, T., \& McKeachie, W. J. (1991). A manual for the use of the motivated strategies for learning questionnaire (MSLQ). ERIC Institute of Educational Science.

Reimann, P. (2019). Methodological progress in the study of self-regulated learning enables theory advancement. Learning and Instruction, (xxxx), 101269. doi:https://doi.org/10.1016/J.LEARNINSTRUC.2019.101269.

Rummel, N., Walker, E., \& Aleven, V. (2016). Different futures of adaptive collaborative learning support. International Journal of Artificial Intelligence in Education, 26(2), 784-795. https://doi.org/10.1007 /s40593-016-0102-3.

Schutz, P. A., \& Davis, H. A. (2000). Emotions and self-regulation during test taking. Educational Psychologist, 1520(907137492), 37-41. https://doi.org/10.1207/S15326985EP3504.

Scrimin, S., Patron, E., Ruli, E., Pagui, C. E. K., Altoè, G., \& Mason, L. (2018). Dynamic psychophysiological correlates of a learning from text episode in relation to reading goals. Learning and Instruction, 54(February 2017), 1-10. https://doi.org/10.1016/j.learninstruc.2018.01.007.

Shen, C., Vasilyeva, M., \& Laski, E. V. (2016). Here, but not there: Cross-national variability of gender effects in arithmetic. Journal of Experimental Child Psychology, 146, 50-65. https://doi.org/10.1016/j. jecp.2016.01.016.

Sivic, J., \& Zisserman, A. (2003). Video Google: A text retrieval approach to object matching in videos. In Proceedings of ninth IEEE international conference on computer vision (pp. 1-8). Nice: IEEE. https://doi. org/10.1109/ICCV.2003.1238663.

Sonnenberg, C., \& Bannert, M. (2015). Discovering the effects of metacognitive prompts on the sequential structure of srl-processes using process mining techniques. Journal of Learning Analytics, 2(1), 72-100.

Strang, A. J., Funke, G. J., Russell, S. M., Dukes, A. W., \& Middendorf, M. S. (2014). Physio-behavioral coupling in a cooperative team task: Contributors and relations. Journal of Experimental Psychology: Human Perception and Performance, 40(1), 145-158. https://doi.org/10.1037/a0033125.

Su, Y., Li, Y., Hu, H., \& Rosé, C. P. (2018). Exploring college English language learners' self and social regulation of learning during wiki-supported collaborative reading activities. International journal of computer-supported collaborative learning, 1-26. https://doi.org/10.1007/s11412-018-9269-y. 
Taub, M., Azevedo, R., Rajendran, R., Cloude, E. B., Biswas, G., \& Price, M. J. (2019). How are students' emotions related to the accuracy of cognitive and metacognitive processes during learning with an intelligent tutoring system? Learning and Instruction, (July 2018), 101200. https://doi.org/10.1016/j.learninstruc.2019.04.001.

Thiede, K. W., Griffin, T. D., Wiley, J., \& Redford, J. S. (2009). Metacognitive monitoring during and after reading. In Handbook of metacognition in education (pp. 85-106). New York: Routledge/Taylor \& Francis Group.

Winne, P. H. (2010). Improving measurements of self-regulated learning. Educational Psychologist, 45(4), 267276. https://doi.org/10.1080/00461520.2010.517150.

Winne, P. H. (2011). A cognitive and metacognitive analysis of self-regulated learning. In D. H. Schunk \& B. J. Zimmerman (Eds.), handbook of self-regulation of learning and performance (pp. 15-32). https://doi. org/10.4324/9780203839010.ch2.

Winne, P. H. (2015). What is the state of the art in self-, co- and socially shared regulation in CSCL? Computers in Human Behavior, 52, 628-631. https://doi.org/10.1016/j.chb.2015.05.007.

Winne, P. H. (2019). Paradigmatic dimensions of instrumentation and analytic methods in research on selfregulated learning. Computers in Human Behavior, 96, 285-289. https://doi.org/10.1016/j.chb.2019.03.026.

Winne, P. H., \& Hadwin, A. F. (1998). Studying as self-regulated learning. In D. J. Hacker, J. Dunlosky, \& A. C. Graesser (Eds.), Metacognition in educational theory and practice (pp. 277-304). New York: Routledge.

Winne, P. H., Nesbit, J. C., \& Popowich, F. (2017). nStudy: A system for researching information problem solving. Technology, Knowledge and Learning, 22(3), 369-376. https://doi.org/10.1007/s10758-017-9327-y.

Winne, P. H., \& Perry, N. E. (2000). Measuring self-regulated learning. In: Handbook of self-regulation (pp. 531565). https://doi.org/10.1016/B978-012109890-2/50045-7.

Wolters, C. A. (2003). Regulation of motivation: Evaluating an underemphasized aspect of self-regulated learning. Educational Psychologist, 38(4), 189-205. https://doi.org/10.1207/S15326985EP3804_1.

Xu, N., Wang, Y., Chen, X., \& Lian, H. (2019). Vector quantization: Timeline-based location data extraction and route fitting for crowdsourcing. In Lecture notes in electrical engineering (pp. $\mathrm{xxx}-\mathrm{xxx}$ ). Singapore: Springer. https://doi.org/10.1007/978-981-13-6553-9_4.

Zheng, J., Xing, W., \& Zhu, G. (2019). Examining sequential patterns of self- and socially shared regulation of STEM learning in a CSCL environment. Computers \& Education, 72, 1-33. https://doi.org/10.1016/j. compedu.2019.03.005.

Zheng, L., \& Yu, J. (2016). Exploring the behavioral patterns of co-regulation in mobile computer-supported collaborative learning. Smart Learning Environments, 3(1), 1. https://doi.org/10.1186/s40561-016-0024-4.

Zhou, M. (2013). Using traces to investigate self-regulatory activities: A study of self-regulation and achievement goal profiles in the context of web search for academic tasks. Journal of Cognitive Education and Psychology, 12(3), 287-306.

Zimmerman, B. J. (2013). From cognitive modeling to self-regulation: A social cognitive career path. Educational Psychologist, 48(3), 135-147. https://doi.org/10.1080/00461520.2013.794676.

Publisher's note Springer Nature remains neutral with regard to jurisdictional claims in published maps and institutional affiliations.

\section{Affiliations}

\section{Márta Sobocinski ${ }^{1} \cdot$ Sanna Järvelä ${ }^{1} \cdot$ Jonna Malmberg ${ }^{1} \cdot$ Muhterem Dindar $^{1} \cdot$ Antti Isosalo $^{2} \cdot$ Kai Noponen ${ }^{2}$}

1 Learning and Educational Technology Research Unit, University of Oulu, P.O.BOX 2000, FIN-90014 Oulu, Finland

2 Center for Machine Vision and Signal Analysis, University of Oulu, Oulu, Finland 